San Jose State University

SJSU ScholarWorks

Master's Theses

Master's Theses and Graduate Research

1989

\title{
Psychosocial factors influencing success with continuous ambulatory peritoneal dialysis
}

Susan K. Healy

San Jose State University

Follow this and additional works at: https://scholarworks.sjsu.edu/etd_theses

\section{Recommended Citation}

Healy, Susan K., "Psychosocial factors influencing success with continuous ambulatory peritoneal dialysis" (1989). Master's Theses. 3142.

DOI: https://doi.org/10.31979/etd.hzsc-m3pp

https://scholarworks.sjsu.edu/etd_theses/3142

This Thesis is brought to you for free and open access by the Master's Theses and Graduate Research at SJSU ScholarWorks. It has been accepted for inclusion in Master's Theses by an authorized administrator of SJSU ScholarWorks. For more information, please contact scholarworks@sjsu.edu. 


\section{INFORMATION TO USERS}

The most advanced technology has been used to photograph and reproduce this manuscript from the microfilm master. UMI films the text directly from the original or copy submitted. Thus, some thesis and dissertation copies are in typewriter face, while others may be from any type of computer printer.

The quality of this reproduction is dependent upon the quality of the copy submitted. Broken or indistinct print, colored or poor quality illustrations and photographs, print bleedthrough, substandard margins, and improper alignment can adversely affect reproduction.

In the unlikely event that the author did not send UMI a complete manuscript and there are missing pages, these will be noted. Also, if unauthorized copyright material had to be removed, a note will indicate the deletion.

Oversize materials (e.g., maps, drawings, charts) are reproduced by sectioning the original, beginning at the upper left-hand corner and continuing from left to right in equal sections with small overlaps. Each original is also photographed in one exposure and is included in reduced form at the back of the book. These are also available as one exposure on a standard $35 \mathrm{~mm}$ slide or as a 17" $\times 23^{\prime \prime}$ black and white photographic print for an additional charge.

Photographs included in the original manuscript have been reproduced xerographically in this copy. Higher quality $6^{\prime \prime} \times 9^{\prime \prime}$ black and white photographic prints are available for any photographs or illustrations appearing in this copy for an additional charge. Contact UMI directly to order.

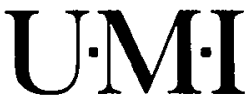

University Microfilms International

A Bell \& Howell Information Company

300 North Zeeb Road. Ann Arbor, MI 48106-1346 USA

$313 / 761-4700 \quad 800 / 521-0600$ 

Order Number 1938695

Psychosocial factors influencing success with continuous ambulatory peritoneal dialysis

Healy, Susan Kaye, M.S.

San Jose State University, 1989

$\mathrm{U} \cdot \mathrm{M} \cdot \mathrm{I}$

300 N. Zeeb Rd.

Ann Arbor, MI 48106 



\title{
PSYCHOSOCIAL FACTORS INFLUENCING \\ SUCCESS WITH CONTINUOUS \\ AMBULATORY PERITONEAL DIALYSIS
}

\author{
A Thesis \\ Presented to \\ The Faculty of the Department of Nursing \\ San Jose State University
}

In Partial Fulfillment

of the Requirements for the Degree

Master of Science

\author{
by \\ Susan K. Healy \\ June, 1989
}


APPROVED FOR THE DEPARTMENT OF NURSING

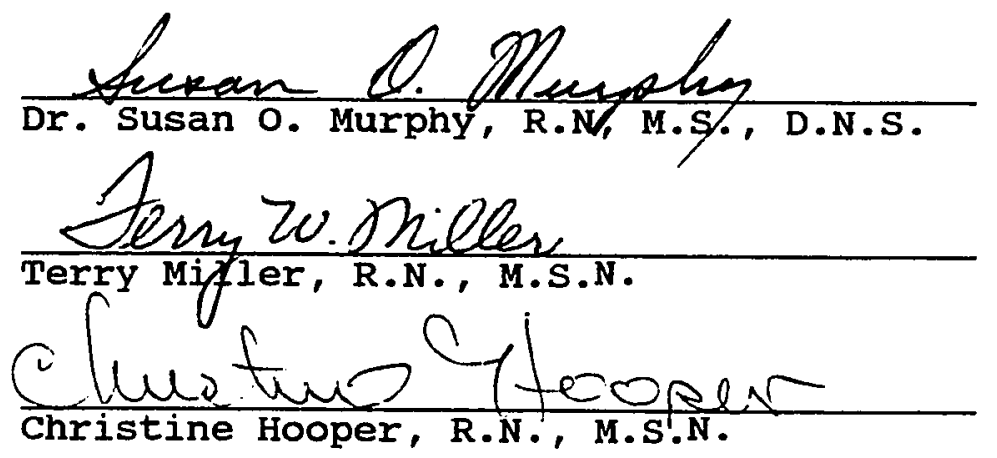

APPROVED FOR THE UNIVERSITY

Herexe He thexpere 


\begin{abstract}
This study looked at patients using continuous ambulatory peritoneal dialysis (CAPD), a form of self care home dialysis. This study attempted to clarify factors possibly related to patient success with CAPD. A tool was utilized that addressed mood and ability to handle crisis, tolerance for stress, personality structure, cognitive function, self care habits, body image, and acceptance of treatment by relatives. The goal of the study was to determine if there was a relationship between a patient's score on the tool, and success with CAPD. The sample consisted of 37 end stage renal disease (ESRD) patients. Qualitative information was gathered via interviews with four successful CAPD patients to ascertain their impression of what led to their success with CAPD. Quantitative analysis confirmed a positive correlation between composite scores on the tool, and degree of success with CAPD. Qualitative data produced interesting insights into patient perceptions regarding success on CAPD.
\end{abstract}




\section{ACKNOWLEDGEMENT}

Many thanks for encouragement and never failing support from my best friends - my family - Jim, Kevin and Julia. 
TABLE OF CONTENTS

Chapter

Page

INTRODUCTION $. . . \cdot . \cdot . \cdot . \cdot . \cdot . \cdot . \cdot . \cdot . \cdot . \cdot \cdot 1$

Problem and Need . . . . . . . . . . . 1

Purpose of this study . . . . . . . . . . . 3

Definition of Terms . . . . . . . . . . . 4

Organization of Thesis . . . . . . . . . . . 5

CONCEPTUAL FRAMEWORK AND REVIEW OF LITERATURE • . • • . 6

Conceptual Framework . . . . . . . . . . . 6

Review of the Literature . . . . . . . . . . 7

METHODOLOGY . . . . . . . . . . . . . . . . 14

Data Collection: Sample, Setting, Methods . . . 15

Reliability of Assessment Tool and Scoring . 16

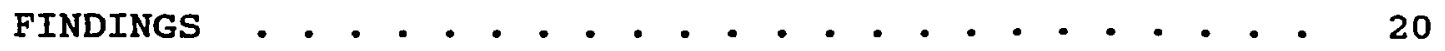

Quantitative Data . . . . . . . . . . . 20

Patient Success with CAPD . . . . . . 20

Participation in Care . . . . . . . . 20

Peritonitis Rate . . . . . . . . . 21

Functional Level . . . . . . . . . . 21

Acceptable Lab Values . . . . . . . . . 21

Length of Treatment . . . . . . . . . 21

How Treatment Ended . . . . . . . . . . 22

Success of Treatment . . . . . . . . . 22

Statistical Analysis of Dialysis Screening

Tool . . . . . . . . . . . . 22 
Qualitative Data . . . . . . . . . . . 23

Background Data . . . . . . . . . . 23

Analysis and Interpretation . . . . . . . 24

Reason for Choosing CAPD . . . . . . . 25

Personal Degree of Success . . . . . . 25

Personal Strengths . . . . . . . . . 26

Difficult Aspects . . . . . . . . . . 26

Mood, Independence, Determination, Self Care 27

Cognitive Function . . . . . . . . . . 28

Body Image . . . . . . . . . . . . 28

Handle Environmental Stress . . . . . . . 29

Strong Personality Structure . . . . . . 29

Support and Significant others . . . . . 30

Additional Observations . . . . . . . 30

Limitations . . . . . . . . . . . 36

Sumary . . . . . . . . . . . . . . . 38

REFERENCES . . . . . . . . . . . . . . . . 4 40

APPENDIX A . . . . . . . . . . . . . . . . . 43

Instrument . . . . . . . . . . . . . . 43

APPENDIX B . . . . . . . . . . . . . . . . . . . 45

Interview Guide .. . . . . . . . . . 45 45

APPENDIX C . . . . . . . . . . . . . . . . . . . . . . 48

Reliability of Tool . . . . . . . . . . . . 48

APPENDIX D . . . . . . . . . . . . . . . 57

Frequency Graphs . . . . . . . . . . . . 57 


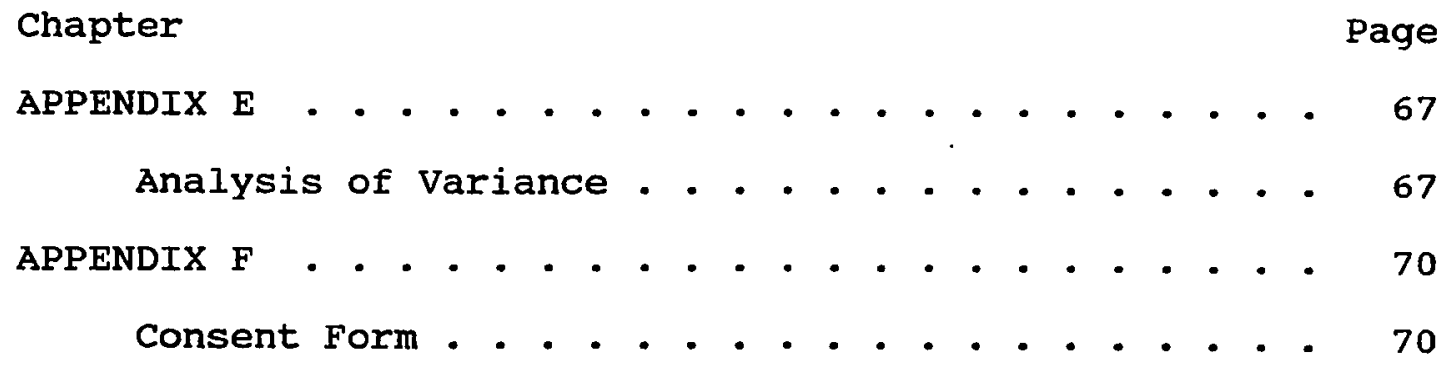


Chapter 1

INTRODUCTION

An increasing number of individuals are accepting responsibility for more of their own medical care at home. Today, this holds true for patients with renal failure facing long-term chronic dialysis. Although the familiar option of hemodialysis in the clinic or hospital setting is still readily available, many people are choosing to perform their own dialysis at home, whether it be hemodialysis or peritoneal dialysis. Any patient choosing to accept the responsibility to dialyze at home must participate in a very rigorous training period, learn much technical information, and agree to total compliance with the techniques and directions they are given.

Problem and Need

Related to the issues of compliance and training is the issue of successful accomplishment of home dialysis. According to the current statistics of the Continuous Ambulatory Peritoneal Dialysis Registry of the National Institutes of Health (NIH), $9 \%$ of the patients training for home peritoneal dialysis "drop out" at six months, another 9\%, at one year. After 18 months, the probability of dropping out increases by $6 \%$ every six months. By three years, $44 \%$ of patients have discontinued home peritoneal dialysis in favor of an alternative dialysis modality (National Institutes of Health [NIH], 1981-1986). 
There is some public awareness of the plight of the renal patient, due to media coverage of fund raising for home dialysis machines, and the campaign by transplant facilities to increase availability of cadaver kidneys for transplantation. This publicity has possibly lent an air of glamour to the condition of renal failure when, in reality, the life of a renal failure patient remains a long-term struggle. Treatment is, at best, tedious and time consuming; at worst, almost intolerable (Auer, 1982). Not every patient with end stage renal disease is an appropriate candidate for home dialysis. Selecting patients for this type of dialysis therapy requires careful consideration by a dialysis team. Typically, this team consists of a nephrologist, a dialysis coordinator or head nurse, and a social worker. Some nephrologists believe every dialysis patient is a potential candidate for continuous ambulatory peritoneal dialysis (CAPD). Others feel that half the dialysis population would be suitable candidates. A more realistic figure is probably 25\%-30\% (Arenz, 1982, p. 950). Regardless, patients that enter home training programs and then discontinue them, do so at significant cost to themselves and their training center.

Clinical experience indicates there may be identifiable psychosocial traits and characteristics that aid the renal team in identifying patients who will be successful with home peritoneal dialysis (Ebrahim, Gulledge \& Mign, 1982). 
Therefore, it would be valuable if these characteristics could be identified and measured prior to the initiation of dialysis.

The costs of dropping out from home dialysis training programs vary with each patient, but can be high in terms of time, medical complications, frustration, and disappointment. The identification of psychosocial characteristics that could assist in the selection of appropriate patients for home dialysis training should at least alleviate some of the personal costs in frustration and disappointment encountered by these patients.

$$
\text { Purpose of this study }
$$

This study looked at patients using continuous ambulatory peritoneal dialysis, a form of self care home dialysis. This study attempted to further clarify those factors which might be related to patient success with CAPD. There were two parts to the study: a quantitative phase and a qualitative phase. The first phase was a retrospective evaluation of the relationship between patient success on CAPD and his/her score on a screening tool used in a dialysis center. The screening tool attempted to address certain psychosocial factors identified in previous studies as being related to success with CAPD. The hypothesis of this quantitative phase of the research was that the scores on the specified screening tool would be positively related to successful home peritoneal dialysis. 
However, evaluation of this tool would be incomplete without also identifying what patients themselves saw as contributing to their success with CAPD. Therefore, the second phase of the study was undertaken.

The purpose of the second phase of the study was to ascertain what patients perceived to be the reasons for their success with home peritoneal dialysis. Interviews were conducted with successful CAPD patients and qualitative analysis was used to identify those factors which patients saw as contributing to their success.

Definition of Terms

1. ESRD Patient - an individual suffering from end stage renal disease requiring renal replacement therapy.

2. CAPD - continuous ambulatory peritoneal dialysis. A portable, primarily internal system of dialysis that uses the continuous presence of dialysis fluid in the peritoneum. Instilled through a permanent catheter and transmitted by osmosis and diffusion, the fluid equilibrates with blood chemistries. It is exchanged with fresh fluid in a ten minute process that is repeated approximately four times a day.

3. SuccessfuI CAPD patient - an ESRD patient that has been trained to accomplish CAPD, and has accomplished the technique for a period of 12 months or greater, and during time on the therapy has: 
- actively participated in all care, including exchanges, and exit site care

- maintained a peritonitis rate at or below the national average of 1.3 episodes per year (National Institutes of Health [NIH], 1981-1986)

- maintained functional level at least at the level established prior to initiation of CAPD

- maintained laboratory values within acceptable parameters established for individual patient by their nephrologist

4. Hemodialysis - treatment for ESRD utilizing the artificial kidney machine.

5. Nephrology nurse - a registered nurse that has received specialized training in the care of ESRD patients.

6. ESC - exit site care - daily cleansing of the abdominal exit site of the peritoneal catheter. Organization of Thesis

This study will be presented as follows: Chapter 2 constitutes the conceptual framework of the study, and the literature review. In Chapter 3, the methodology utilized for this study will be presented. In Chapter 4, the findings of the quantitative and qualitative phases of this study are discussed, and in Chapter 5, conclusions and recommendations derived from the study are presented. 
Chapter 2

CONCEPTUAL FRAMEWORK AND REVIEW OF LITERATURE

Conceptual Framework

The conceptual framework for this study was derived from the work of Ebrahim, Gulledge and Mign (1982). They identified psychosocial factors that might predict success with CAPD. The framework for this study was developed to deal with the increasing problem of "drop out" from existing CAPD programs by identifying psychosocial factors that may increase this probability. This was accomplished by looking at a screening tool based on the psychosocial factors identified by these researchers. By assessing patients with such a tool, placement of appropriate patients on CAPD should increase, thereby decreasing drop out by patients inappropriately placed on the modality.

According to Ebrahim, Gulledge and Mign, although CAPD is a series of time-consuming, tedious tasks for the patient, CAPD offers the patient greater independence and enables the patient to take an active role in $\mathrm{his} / \mathrm{her}$ treatment. Over a two year period, 46 patients were evaluated for possible CAPD.

A social worker interviewed the families or relatives in regard to the patient's financial and functional capabilities, communication and support, comprehension of illness and dialysis, and prior adjustment to stresses. No formal psychological tests were administered to any patient. 
Instead, information assembled from a careful history, the mental status examination, and patient and family interviews was discussed with the renal team in considering why a patient would or would not be likely to succeed with CAPD. During the interviews and observation of these patients, eight psychosocial factors were identified that indicated patients more likely to succeed with CAPD. These factors included: mood, independence, cognitive function, body image, previous ability to handle crises, tolerance for stress, personality structure, and acceptance of the treatment by relatives.

The conclusions of Ebrahim, Gulledge, and Mign are impressionistic, and in need of further theoretical development and testing. Studies are needed to assess more precisely the psychological features and those attributes possibiy predictive of satisfactory use of CAPD. This study builds on this ground-breaking theoretical work.

Review of the Literature

Prior to 1975, the only options for end stage renal failure patients were hemodialysis and transplantation. With the advent in 1975 of continuous ambulatory peritoneal dialysis, end stage renal failure patients were given the third option for maintenarice therapy of their renal failure. CAPD, as a method of home dialysis, assumes that patients will be rehabilitated most satisfactorily in their own environment (Arenz, 1982, p. 950). Home or in-center 
hemodialysis requires sophisticated machinery. The blood is removed from the body through an extracorporeal circuit and pumped into a dialyzer, or artificial kidney. The blood passes on one side of a semipermeable membrane, the dialysate passes on the other side of the membrane. Via the processes of osmosis and diffusion, waste products and water are removed from the blood stream.

CAPD negates the need for expensive, sophisticated machinery by using the body's own semipermeable membrane, the peritoneum. The peritoneal membrane forms a closed sac around the abdominal organs. A permanent peritoneal catheter is surgically placed in the abdominal space. Dialysate is instilled into the space by gravity. Again, through osmosis and diffusion, waste products are removed from the blood into the dialysate. This is a slow dialysis process, with each "dwell" of dialysate lasting four to six hours. The spent dialysate is then drained and discarded, and fresh dialysate infused into the abdominal space.

Due to the ever present risk of peritonitis with CAPD, adherence to the exact exchange procedure and aseptic technique is imperative. The slightest modification in the procedure may introduce bacteria into the system, which can lead to peritonitis (Arenz, 1982, p. 948).

As mentioned, selecting patients for CAPD requires careful consideration by the dialysis team, as well as the patient approaching dialysis. According to Arenz (1982), 
$25 \%-30 \%$ of end stage renal disease patients approaching dialysis are suitable candidates for CAPD.

The intensive training period of 2-3 weeks required to teach patients to accomplish CAPD at home, coupled with the close follow-up required by the CAPD staff, make drop out from the CAPD program costly and draining for staff and patient. According to the National Institutes of Health CAPD Registry, the current drop out rate for CAPD is $44 \%$ at three years (National Institutes of Health [NIH], p. 5-2). In terms of staff time and energy, and finances, this drop out rate represents one very negative aspect of CAPD. Although it is tedious and time consuming, CAPD does offer the prospect of greater independence, and enables the patient to take an active role in his or her own treatment (Ebrahim, et al., 1982, p. 944).

A search of nursing and allied health literature reveals little research on the topic of predicting which patients will be successful on CAPD. Most of the literature regarding CAPD deals only with medical aspects, technical advances, and alternatives. Information on psychosocial factors of patients suitable for the therapy is limited. Several studies have been done in the related area of compliance with medical regimens (Becker \& Malman, 1975; O'Brien, 1980). A number of these studies relate to the Health Belief Model (Becker \& Malman, 1975). Most studies have produced consistent findings that yield support for a 
conceptual model of compliant behavior. Some reviewers have concluded that the model provides a satisfactory explanation for health behavior, whether preventative, or action taken by persons diagnosed as ill (Becker \& Malman, 1975). However, the emphasis of these studies is on compliance with prescribed medical regimens for specific diagnoses: rheumatic fever, otitis media, and hypertension (O'Brien, 1980). These studies do not address the issues of psychosocial predictors of success in a complex home care regimen.

Some studies have been done in the related area of assessment of candidates for hemodialysis. In a study done in Seattle (Sand, Livingston \& Wright, 1966), all patients receiving hemodialysis at a large ESRD center over a period of three years were rated by the unit's "psychological team." This team included from 6 to 13 nurses, nurses" aides, and physicians who had frequent contact with new patients admitted for care. Each staff member gave a rating of either superior, adequate, or poor in response to three questions regarding patient's cooperation with treatment, emotional adjustment, and likelihood of success on the treatment. The investigators did not specify at what point in time after initiation of therapy these ratings were performed. Staff were also invited to make comments on the form justifying their scores. 
Those patients who were seen as adjusting most successfully to hemodialysis demonstrated (a) higher intelligence, (b) less defensive attitudes about admitting to anxiety or emotional difficulty, (c) less reliance on emotional defenses that involved physical symptoms (hypochondriasis and hysteria), and (d) more satisfactory emotional support from family members.

Another study conducted by O'Brien (1980) was designed to determine whether the presence of a strong support system in terms of family and close friends was associated with positive adjustment and compliance on the part of patients undergoing chronic hemodialysis treatments. One hundred and twenty-six patients were interviewed at the initiation of dialysis and 62 of the original sample were interviewed 3 years later. This research indicated that perceived support of family and significant others strongly correlated with positive adjustment and compliance behaviors. Definitions of "positive adjustment and compliance behaviors" were determined by primary staff working with patients. These studies directly or indirectly looked at some of the same factors identified by Ebrahim, Gulledge, and Mign, such as intelligence, coping ability, and emotional support of family and significant others. There are parallels between hemodialysis patients and CAPD patients in that they both suffer from end stage renal disease, the resulting uremia, and the necessity for long term chronic therapy. However, 
the differences in the therapies require different coping styles and data obtained from studies with hemodialysis patients do not necessarily apply directly to CAPD patients.

A study conducted by Eichel (1986) points to the differences in stressors identified by CAPD patients versus hemodialysis patients. In this study, stress factors and coping strategies reported by 30 patients on CAPD were compared to those reported from a sample of 35 hemodialysis patients. The findings suggested that although the sources of stress and coping strategies of the two groups were similar, CAPD subjects experienced less stress, and identified different stressors as having the greatest priority. The highest priority stressor for hemodialysis patients was limitation of fluids, whereas for CAPD patients, the highest priority stressor was fatigue. other items mentioned as stressful for CAPD patients included limitation of physical activities, muscle cramps, decrease in sexual drive, and body image.

One study by Whittaker (1984) identified psychosocial factors which appeared to discriminate between adjusted and nonadjusted CAPD patients. This study looked at 25 patients that had completed a CAPD training program. Several sources of data were used, including interviews conducted by the primary researcher, two unspecified data collection instruments and review of the patient's medical record. Whittaker concluded that patients who adjust and remain in 
the CAPD program tend to be more venturesome, experimenting and self-sufficient than patients who leave the program. In addition, they were viewed as more resourceful and tolerant of inconvenience and change. The responses of the nonadjusted group demonstrated a tendency toward a high degree of threat sensitivity and feelings of inferiority. They were less tolerant of change and were characterized as having a greater need for social approval and group support. These findings provide support for future research which might further clarify the psychosocial characteristics of successful and non-successful CAPD patients.

This study was designed to clarify and examine the psychosocial factors identified by Ebrahim, Gulledge, and Mign that might impact success with CAPD. 


\section{Chapter 3}

METHODOLOGY

This study incorporated two methodological approaches. Phase one was a retrospective study to determine if patients' scores on a screening tool were positively related to their subsequent success on CAPD. The tool was designed so that high composite scores would indicate a higher expectation of success on CAPD. A low composite score would indicate less probability that the patient would be successful on home dialysis.

The nephrology nurse that developed the screening tool collected data with the instrument for 36 months. Data were collected on all patients during routine screening interviews prior to initiating dialysis (see Appendix A). Following the interview with each patient, prior to his or her selection of a dialysis therapy, the nurse filled out the screening tool, calculated the composite score, and filed this information with the interview form. Until this study was proposed, no evaluation of the screening information had been performed. Phase one of this study retrospectively examined the relationship between these composite scores and actual patient outcomes with dialysis.

Phase two involved in depth interviews with a small number of patients who had experienced success with home dialysis. These interviews were conducted to identify what successful CAPD patients perceived as the reasons for their 
success on the therapy. Patients who have experienced ESRD and dialysis therapy are the best source of information regarding the experience on initiating dialysis, and they have valuable insights regarding what makes a patient appropriate for a chosen therapy. Therefore, patients that met the criteria of being successful on CAPD were interviewed to ascertain what their perceptions were regarding the reasons for their success.

According to Chenitz and Swanson (1985), this form of research provides a method to study patterns known as basic social-psychological processes which account for variation in interaction around a phenomenon or problem. Treece and Treece (1977) also suggested a case study design is useful when one wants in depth information, and is particularly effective when there is a lack of background information or documentation in areas that deserve more extensive investigation.

Data Collection: Sample, setting, Methods

\section{Phase one}

The subjects were ESRD patients that had initiated CAPD at a free standing dialysis clinic in Northern California. Thirty-seven patients had initiated CAPD following the screening interviews. Of these 37 patients, 19 were men, 18 were women. Their ages ranged from 19 to 81 . Several nationalities were represented, but the largest group (15) were Hispanic. When the initial assessments were made, all 
patients were in end stage renal failure, irreversible loss of kidney function necessitating renal replacement therapy to maintain life.

Patient age frequencies were analyzed with ages ranging from 19 to 81 years. Nine patients fell in the 19-40 group, 11 in the 40-60 group, and 17 in the 60-81 group. This distribution is reflective of the increase seen nationally in the geriatric dialysis population.

The sample of 37 patients' scores on the screening tool were compared to their success on CAPD. Criteria for "success with home peritoneal dialysis" was defined as being on home peritoneal dialysis for a period of 12 months, and during that time to have actively participated in all care, including exchanges and exit site care, and not to have exceeded the national average number of cases of peritonitis. Additionally, the patient must have maintained a level of functioning at least equivalent to that level when CAPD was initiated, and maintained laboratory values within acceptable parameters set by the nephrologists for the individual patient.

\section{Reliability of Assessment Tool and scoring}

Reliability of the nurse's scoring was tested by comparing her scores with those of another independent nurse rater. Both nurses were familiar with the patients, one scoring the patients during initial interviews, and the other scoring the patients shortly after initiation of 
training. The ratings on each of the eight items included in the instrument were cross-tabulated and Kendall's tau-b statistic was utilized (see Appendix C). Kendall's tau-b statistic produces a measure of correlation between ordinal variables ranging from -1 to 1 : 0 means no correlation, 1 means perfect correlation, -1 inverse perfect correlation. Items 1 through 7 showed a moderate to high degree of correlation, ranging from -85 to .95 . Item 8 showed a slightly smaller, although significant level of correlation (see Appendix C).

The nurse's composite measure for each patient, obtained by adding up scores from the eight items, were compared using the regression function (see Appendix $C$. Again, there was a high linear correlation between the scores given by the two nurses. Scores obtained by the second nurse were used only to establish reliability of the first nurse's scores. Only scores obtained by the interviews were used during analysis of the quantitative data.

Phase Two

For the qualitative portion of the study, only patients from the center that met the criteria of being successful with CAPD were eligible for the interviews. of the 37,14 were eliminated because they had not met the criteria of being on the therapy for a full 12 months. Some of these patients had experienced failure with the therapy, and some 
had been transplanted, or died. Six patients that met the criteria of being on CAPD for 12 months were eliminated, three for high rates of peritonitis, one for inability to maintain lab values within acceptable parameters, and two because they did not participate in their care, and in fact were having family members perform all exchanges and related care.

Ten patients met all criteria, but were not eligible because they had died, had received a kidney transplant, or had left the CAPD modality for reasons other than therapy failure before completion of the study. Seven patients met all the criteria for success with CAPD. Of these seven, four were randomly selected and invited to participate in an interview. Three of these patients were males ranging in ages from 34-72, and one was a 32 year old female. Those invited to participate in an interview signed a consent form indicating that they understood the purpose of the study, and were assured of confidentiality. Each interview was conducted by the researcher and lasted for approximately 30 to 60 minutes.

The interviews were conducted in the clinic setting during routine visits or during routine home visits. An interview guide was utilized to assure that all patients would be asked the same questions (see Appendix B), but the questions were not necessarily asked in the same order. The patients were encouraged to describe their dialysis 
experience in narrative form as thoroughly as possible. The researcher asked clarifying questions to make sure relevant material was covered. Patients were encouraged to discuss not only what they felt were their strengths in dealing with CAPD, but also what presented the greatest obstacles. They were asked to describe their personal perception of their success, and to identify those things to which they attributed their success. In addition, patients were asked to what degree they felt each of the eight characteristics from the assessment tool impacted their success with CAPD. Each interview was conducted by the same researcher. Each interview was tape recorded, and note taking was kept to a minimum. The analysis of qualitative data is perhaps the most demanding and least examined aspect of the qualitative research process. For this study, content analysis was used to analyze the material gathered. Each tape was reviewed by the researcher and notes were taken according to the categories of information. The taped responses were classified according to these categories.

Data from the interviews were organized to meet the objective of the study which was to ascertain what patients perceived to be the reasons for their success with CAPD. Therefore, responses were organized into categories following the interview objectives included in Appendix B, and the responses to the perceived importance of the eight items from the Dialysis Screening Tool (Appendix A). 


\section{Chapter 4 \\ FINDINGS \\ Quantitative Data}

The data from this study was analyzed to determine if correlations existed between the scores on the Dialysis Screening Tool and success with CAPD. Additionally, the reliability of the Dialysis screening Tool was tested. Data from 37 Dialysis Screening Tools were analyzed.

\section{Patient Success with CAPD}

For the purpose of this study, success with CAPD was operationally defined as:

1. Active participation in self care, AND

2. Peritonitis rate at or below the national average, AND

3. Functional level at least at the level established prior to initiation of CAPD, AND

4. Laboratory values within acceptable parameters, AND

5. Either duration of treatment of at least 12 months, OR transplant, OR both.

Using the patients' medical record data, the frequency of these criteria in the 37 patients studied were analyzed and plotted onto graphs (Appendix D).

\section{Participation in care}

Seventy-five and seven tenths percent were categorized as participating, and $24.3 \%$ were categorized as not 
participating in their care.

\section{Peritonitis Rate}

Seventy-eight percent of the patients studied had peritonitis episodes not exceeding the national average. Twenty-two percent of the patients exceeded the national average number of peritonitis episodes.

\section{Functional Leve1}

Eighty-one percent of the patients were categorized as maintaining their functional level at least at the level established prior to initiation of CAPD. Nineteen percent were categorized as not maintaining their functional level. Acceptable Lab Values

Ninety-two percent were categorized as maintaining acceptable laboratory values as established by their nephrologist. Eight percent were categorized as unable to maintain satisfactory lab values.

\section{Length of Treatment}

Six patients were on CAPD one month or less. Four patients were on CAPD 2-6 months. Ten patients were on CAPD from 7-12 months. Twelve patients were on CAPD from 13-16 months, and one patient each was on CAPD 26, 31, 32, 42, and 44 months.

These findings were further categorized into two groups: patients on CAPD less than 12 months, and patients on CAPD 12 months or longer. Of the total sample, $48.6 \%$ of the patients were on CAPD less than 12 months. Fifty-one 
on CAPD 12 months or longer. Of the total sample, $48.6 \%$ of the patients were on CAPD less than 12 months. Fifty-one and four tenths percent were maintained on CAPD longer than 12 months. This was close to a 50\% split.

Additional data were examined for frequencies.

How Treatment Ended

The following categories were examined:

transplant

death

cease (discontinued CAPD for reasons other than transplant or death)

continues

Eighteen and nine tenths percent of the patients received renal transplants, $21.6 \%$ died, $24.3 \%$ discontinued CAPD, and $35.1 \%$ of those studied were still on CAPD at the time of the study.

Success of Treatment

Patients were categorized as successful (meeting all of the listed criteria) or unsuccessful (not meeting one or more of the listed criteria). Interestingly, this was close to a $50 \%$ split, with $51.4 \%$ of the patients being categorized as unsuccessful, and $48.6 \%$ categorized as successful with CAPD.

Statistical Analysis of Dialysis Screening Tool SPSS/PC was used to process the data. This type of correlation research program was selected because the 
The mean scores on the Dialysis Screening Tool were significantly different for unsuccessful and successful patients (based on t-test and one way analysis of variance). The $95 \%$ confidence intervals were respectively, 19.3 to 22.1, and 11.8 to 17.4. Patients categorized as successful scored from 19.3 to 22.1 on the tool, whereas patients categorized as unsuccessful scored 11.8 to 17.4 on the tool $95 \%$ of the time.

Use of the tool to predict classification of the patient in either the successful or unsuccessful group was accurate in $79.38 \%$ of the cases. If one assumes that assignment to modality by chance would produce successful placement $50 \%$ of the time, use of the tool improved that chance of successful placement by $30 \%$ - from $50 \%$ to $79.38 \%$.

\section{Qualitative Data}

\section{Background Data}

The four interviewees ranged in age from 32-81 years of age. Those interviewed were engaged in a variety of occupations and activities. One was a retired grocer, one a music teacher working part-time giving private music lessons, one a male on full disability doing odd jobs such as car repairs and light construction. The female subject was a full time secretary. All of those interviewed either lived with family members, and/or had family or significant others living nearby. Three were married and living with spouses, two had children still in the home. The fourth was 
others living nearby. Three were married and living with spouses, two had children still in the home. The fourth was a widower with no children at home.

One patient had renal failure due to diabetes, one due to trauma, one due to polycystic kidney disease, and one due to amyloidosis. Time on dialysis ranged from 13 months to 30 months. Two patients had experienced CAPD as their initial renal replacement therapy, one had experienced both hemodialysis and transplant prior to initiating CAPD, and one had experienced a transplant after six months on CAPD. Analysis and Interpretation

The interview data analyzed were according to 12 categories of data. These included:

1. Reason for choosing CAPD

2. Personal degree of success

3. Personal strengths

4. Difficult aspects

Responses received regarding perceived importance of the following eight psychosocial factors identified on the tool were analyzed:

1. Positive mood, independence, determination, attention to self care

2. Ability to test reality

3. Positive cognitive function

4. Positive body image

5. Previous ability to handle crisis 
8. Support and acceptance of significant others Reason for choosing CAPD

Responses were varied and very individualized. Two patients declared a strong aversion to hemodialysis. Both had family or close friends experience the treatment and found it repugnant. One of these patients was willing to do hemodialysis if it was his "only chance"; the other stated she would not go on hemodialysis even if it meant her death.

The other two patients cited their desire for independence and freedom as their primary reason for choosing CAPD. The two patients expressing aversion to hemodialysis also mentioned independence as secondary reasons for their selection of CAPD.

\section{Personal Degree of Success}

All patients perceived themselves as doing well on CAPD. "I'm doing great, I feel almost normal," was a typical response. All patients interviewed expressed amazement that the drop out rate for CAPD was so high. Additionally, all four patients expressed that they could not understand anyone not trying CAPD. Their bias was strong and was expressed frequently throughout the interviews. One patient summarized it this way: Why would anyone go to the clinic three times a week to get treatment? They could be home with their families, and doing their own thing. I guess if $I$ was stuck in a wheelchair, or crippled, or something, I'd do hemo- 
and doing their own thing. I guess if I was stuck in a wheelchair, or crippled, or something, I'd do hemo'cause it wouldn't matter then. Otherwise, no way, this is the only way to go.

one patient described her initiation of CAPD as a "new beginning." She expressed gratitude for the therapy, and felt her success with CAPD made her life worth living.

Another patient, despite feeling successful with CAPD, cited his one case of peritonitis as one of the "worst things I've ever gone through." He stated repeated cases of peritonitis could probably make him consider hemodialysis.

\section{Personal Strengths}

Two common responses were heard when patients discussed the personal strengths that they, as successful CAPD patients, felt they possessed. One response mentioned by all four was independence. "I'm a very independent person, and there isn't anything I can't do."

The second response was a strong appreciation for life. One patient expressed that he valued the therapy as "opposed to the options," and loved life.

Other responses obtained regarding personal strengths included, deep spiritual awareness, personal emotional strength, self sufficiency, and positive attitude.

\section{Difficult Aspects}

Responses to this inquiry were very individual, and covered a wide range of issues. The following responses 
Patient \#1 - "Realizing this is the way your life is going to be from now on. This is what we have to do."

Patient \#2 - Not knowing how, or if the therapy will work, and the fear of peritonitis.

Patient \#3 - Fitting four exchanges a day into busy 1ife. Suggested that three exchanges a day would be perfect.

Patient \#4 - Accepting peritoneal catheter. This patient expressed fear of damaging catheter. Also, patient expressed concern that it made one less physically appealing.

The following response categories dealt with the patients' perceptions of the importance of the eight characteristics addressed on the Dialysis Screening Tool with success on CAPD.

Mood, Independence, Determination, Self Care

As might be anticipated, some patients had difficulty separating the four separate characteristics included in this one question. At this point, the interviewer found it necessary to break the question down into its four categories for clarification.

All four patients agreed that positive mood or positive attitude was very important. All agreed that they were independent and determined, and they felt that a desire for independence was an important factor. One patient stated that being determined was important: "You have to make up 
that being determined was important: "You have to make up your mind that this is what you are going to do, and that's that!"

Attention to self care was deemed important in that all patients felt personal cleanliness to be essential in reducing the risk of peritonitis. One patient suggested that anyone that was not careful about personal care and appearance, was dirty, and bound to get infected.

\section{Cognitive Function}

None of the patients interviewed felt it was necessary for a patient to be intelligent in order to do CAPD. It was perceived as a simple technique that "anyone can learn to do."

One patient did mention that he felt a patient had to be smart enough to "understand about germs, and that you have to be clean, or you'll get infected."

Body Image

In general, the patients interviewed had a very positive attitude about body image and the impact of the peritoneal catheter. The one patient that perceived the presence of the catheter as a major obstacle said, "I just don't go bare chested anymore, I wear a shixt 'cause I don't want to put people off." He allowed that although it was an obstacle, it just took time to get used to it.

The female patient stated, "I don't wear bikinis anymore, but it's no big deal." She went on to say that she 
now thinks of the catheter as another part of her body, like an arm or a leg.

\section{Handle Environmental Stress}

"This is not stressful," "not much stress involved." Patients interviewed did not perceive CAPD as a stressful procedure, or a stressful intrusion into their lives. They felt that ability to handle stress wasn't tremendously important, no more so that handling the everyday stresses of life. One patient did say, "you can't go fly off the handle at every little thing - you'll drive yourself crazy." one patient felt that she had become more tolerant of stress since going on CAPD. She had "reordered priorities," and enjoyed life more now. There was a common thread observed during the interviews: an appreciation of life and a determination not to consider renal replacement therapy a burden. Often the interviewees mentioned their gratitude to be able to continue life and considered doing CAPD a small price to pay for their improved health. One patient related that after he had gotten sick with renal failure, he adopted a new attitude about life and decided to "turn over" his problems and care to God. He stated that he never lost a night's sleep worrying about problems. "Things always work out."

\section{Strong Personality Structure}

All patients were observed to be well organized and to possess fairly well-developed personality structures. This 
was evidenced by punctuality for interview appointments, concise responses, neat personal appearance, and frequent expressions of very strong opinions. One patient arrived with tape recorder and fresh tape in case the interviewer had forgotten.

In addition, patients tended to agree that a person had to possess a strong personality structure to be successful with CAPD. This was clearly stated by two patients that felt a strong personality structure, or personal control, was necessary in order to deal with the monotony of doing four exchanges a day, 365 days a year. One of these patients had learned isometric exercises and had a very precise routine he accomplished during each exchange to fill the time during drain and fill.

\section{Support and significant others}

On this issue all patients were unanimous. Family support was welcome and greatly appreciated but was not pivotal to success with CAPD. One patient put it this way, "My family's support helps a lot, but my personal decision to do CAPD would not be different with or without them." Interestingly, all four patients interviewed were in situations where they did in fact enjoy strong family support.

\section{Additional observations}

As much was learned by observation of the four patients interviewed as by the interview questions themselves. 
Despite the differences in age, background, primary disease, and previous renal replacement therapy, several commonalities were observed. All patients were articulate, outspoken, and positive. All patients presented themselves for interviews well groomed and with a business like attitude. They expressed an interest in the study being done and felt they had input that could be helpful. Furthermore, all four patients looked on CAPD as a positive choice that they had made. There was a sense of appreciation of the therapy and a gratitude that they were able, and had chosen to do CAPD.

There also was an unspoken sense that these patients willed themselves to be upbeat and positive and as physically well as possible. This was evidenced by phrases such as "I decided," "I can," "I make myself," and "I can do anything!"

Although several reasons were given for choosing CAPD, one reason mentioned by all patients was the desire for independence. If one definition of independence is self reliance, we can postulate that a person that is basically independent will be more willing and able to assume responsibility for their own life and health care.

All four patients felt that they were successful with CAPD and were amazed to hear national drop out rates and peritonitis rates. They found it hard to relate to the high rates of peritonitis and complications experienced by other 
patients.

Two common personal strengths mentioned were independence and appreciation for life. Patients interviewed had experienced various health problems throughout their lives. One had been diagnosed as diabetic and insulin dependent since age 10. Two patients had experienced unsuccessful transplant attempts and one suffered from amyloidosis with advanced complications. Perhaps because of or in spite of these problems, these patients had a real appreciation for life. Their attitude was positive and focused on what they were able to do, not on their limitations.

Difficult aspects mentioned by the patients varied, but these were handled or resolved by taking a positive attitude and willing themselves to "get through it." Difficult aspects were mentioned, but all of the patients felt they had in fact resolved the problem or were "dealing" with it. When the patients were asked for their opinions as to the importance of the characteristics addressed on the Dialysis Screening Tool, their responses were amazingly similar. All agreed that positive mood, independence, determination, and attention to self care were important. None of the patients felt a high degree of intelligence was necessary; in fact, they all believed that a "simple" person could learn the techniques. 
All patients had experienced some degree of challenge to their body image with CAPD, and felt that a patient going on CAPD needed to be aware of the peritoneal catheter placement and how it would affect them. A strong positive body image was seen as an advantage.

None of those interviewed felt an exceptional tolerance for stress was necessary. Most felt that CAPD had not added tremendous stress to their lives, but that in fact their renal failure and initiation of dialysis had given them a greater appreciation for life.

strong personality structure was apparent in those interviewed and observed. In addition, the patients interviewed saw this as an asset to acceptance of and success with CAPD.

Those interviewed were strongly unanimous in their assertion that support of family and significant others was helpful and welcome but not pivotal to success. These patients felt they were independent and self sufficient and would succeed with CAPD without the support of those around them. At the same time, all four interviewed were in close, supportive situations where they enjoyed the support and approval of their loved ones.

The patients interviewed bore out the assumptions regarding the eight characteristics of successful CAPD patients on the Dialysis screening Tool. Those interviewed scored high on the possession of these characteristics, and 
these characteristics were seen to be strongly present during the interviews.

There were three characteristics that the patients interviewed felt were not greatly important. These were clear sensorium and cognitive function, tolerance for stress, and support of significant others. However, those interviewed were articulate, well spoken and bright. All four had a fairly high tolerance for stress using stress reduction methods they had learned, or had reduced stress by accomplishing a reorganization of priorities. Despite the fact that those interviewed felt that support of significant others was not pivotal, all were in situations where they enjoyed high levels of acceptance and support. 


\section{Chapter 5}

\section{CONCLUSIONS AND RECOMMENDATIONS}

This study sought to determine if correlations existed between scores on the Dialysis Screening Tool and success with CAPD. It was found that there was a significant correlation between achieving a high score on the screening tool and meeting success with CAPD; therefore, the original hypothesis was upheld. By using the Dialysis Screening Tool, the prediction rate for success with CAPD was at least $30 \%$ better than that based entirely on chance (assuming that the chance for success, or lack of it, is split 50/50). These findings indicate that a nephrology team utilizing this instrument would have a more accurate indication of the patient's potential for success with CAPD. Some caution is appropriate when using the Dialysis Screening tool as a predictor of success with CAPD. The Pygmalian effect, "what you expect, is what you get," could be set in play by over reliance on this instrument. Studies have been done on the idea of the "self fulfilling prophecy." In a study done by Rosenthal \& Jacobsen (1968), students were assigned totally arbitrary IQ scores. These scores were shared with their teachers who assumed they were legitimate. IQ testing done at the conclusion of the study produced individual scores amazingly close to the arbitrary score assigned. The question can be raised, is this a case of coincidence, or of "what you expect, is what you get?" 
The process of choosing renal replacement therapy involves numerous considerations. The nephrology team has input into the decision by virtue of being the ones to share with the patient the options available; but ultimately, the decision is the patient's. Few facilities would flatly refuse to allow a patient the opportunity to try CAPD if they were determined to do so. Ideally, using the Dialysis Screening Tool would enable the nephrology team to guide the patient toward CAPD, only if they showed reasonable potential for success. At the same time, if the patient were determined to try CAPD and their score did not indicate a high potential for success, the nephrology team would need to be supportive of that decision and aware of the potential for problems.

Ideally, nephrology teams would elect to use the Dialysis Screening Tool as one instrument in their comprehensive program aimed at identifying appropriate CAPD candidates. Scores on the tool need to be considered in conjunction with patient's age, previous dialysis experience, primary disease, physical complications, and other demographic issues such as proximity to the clinic.

Further refinement and study of the Dialysis screening Tool is needed to increase its accuracy in successful prediction of patient success with CAPD. Studies with large numbers of patients approaching dialysis would help to confirm the results of this preliminary study. 


\section{Limitations}

The sample included all economic classes, and several

ethnic groups. A large proportion of those studied, however, represented one ethnic group, Hispanic. Furthermore, the sample was small so caution must be exercised in generalizing results to a larger population. A high degree of internal validity cannot be assured as a nonexperimental design was utilized. Intervening variables were not controlled nor measured.

The instrument used for assessing the psychosocial factors present with each potential CAPD patient was not standardized by the usual rigorous testing. The instrument, however, was field tested for clarity and accuracy by having a second nephrology nurse at the clinic score the same patients without knowing the researcher's scores. These were compared to assure that the tool could be utilized by two different interviewers and obtain comparable results. Further studies need to be done with larger populations to confirm the results of this study. The qualitative portion of the study is particularly vulnerable to subjective bias. It has been pointed out that interviews are always affected by the relationship between the participant and the researcher. 
Summary

It is beyond the scope of this study to determine if the characteristics identified were basic personality traits, or learned during the ravages of chronic illness and adaptation to dialysis. It is also beyond the scope of this study to determine which was most accurate: what was said or what was observed.

The overall adjustment of the renal patient to the treatment regime depends upon many factors. The findings from this study suggest that personal characteristics may be very important, specifically the patient's pre-existing personality, with its inherent strengths and weaknesses. Whether the need for treatment comes suddenly or has been long anticipated, the moment, when reached, is usually accompanied by anxiety and shock. Once a treatment modality has been chosen and the patient is established on that modality, the patient can begin the difficult task of redefining life in accordance with the disease process and treatment program. This "pairing" of patient with dialysis modality is an important step in the process of returning the end stage renal disease patient to a life as productive, meaningful, and enjoyable as possible.

Those involved with the care of ESRD patients can only imagine the pain and turmoil that is experienced by the patient that has been placed on a dialysis modality that is inappropriate. Such a patient must then be prepared for and 
adapt to another dialysis regime. Also, perhaps just as importantly, they must accept that they, or the previous treatment, has "failed." Techniques that are developed to reduce the number of patients placed on inappropriate dialysis regimes will reduce the amount of pain and turmoil experienced by these patients.

This study showed that the use of the Dialysis Screening Tool could improve the prediction rate for appropriate candidates for CAPD by at least $30 \%$. The qualitative phase of this study bore out the conclusions regarding the screening tool in that those patients who demonstrated high levels of the measured characteristics, and obtained high scores on the screening tool, did experience more success with CAPD.

Further study and refinement of the screening tool is needed to improve the prediction rate to levels significantly higher than $30 \%$. This may be done by more elaborate measurements of each of the eight categories on the tool.

This study offers preliminary quantitative and qualitative data regarding a topic that requires closer study by those in nephrology. Further research is needed to refine our ability to predict who will be successful on CAPD, and thus save patients and CAPD staffs the costs and frustration of CAPD dropout. 
REFERENCES 
References

Arenz, R. (1982). Continuous ambulatory peritoneal

dialysis. American operating Room Nurses, 35(5), 946-954.

Auer, J. (1982). Psychological problems in long term care. Nursing Times, 1058-1060.

Becker, M. H., \& Malman, L. A. (1975). Sociobehavioral determinants of compliance with health and medical care recommendations. Medical Care, 13(1), 10-25.

Chenitz, C. W. \& \& Swanson, J. M. (1985). From practice to grounded theory. Menlo Park: Addison-Wesley Publishing Company •

Ebrahim, L. G., Gulledge, A. D., \& Mign, S. (1982). Continuous ambulatory peritoneal dialysis: Psychological factors. Psychosomatics, 23, 944-949. Eichel, E. (1986). Stress and coping in patients on CAPD compared to hemodialysis patients. American Nephrology Nurses Journal, 13, 9-12.

National Institutes of Health. (1987). Characteristics of participants and selected outcome measure for the period January 1, 1981 through August 31, 1986 (NIDD Contract Nos. NO1-AM-3-2244 and N01-AM-3-2245). Potomac, MD, EMMES Corporations.

O'Brien, M. E. (1980). Hemodialysis regimen compliance and social environment. Nursing Research, 29, 250-255. 
Rosenthal, R., \& Jacobson, L. (1968). Pygmalian in the classroom. New York: Holt, Rinehart \& Winston. Sand, P., Livingston, G., \& Wright, R. (1966). Psychological assessment of candidates for a hemodialysis program. Annals of Internal Medicine, 6455, 293. Treece, E. W., \& Treece, J.W. (1977). Elements of research in nursing, (2nd edition), st. Louis: Mosby . Whittaker, A. A. (1984). The influence of psychosocial factors on patient adjustment to continuous ambulatory peritoneal dialysis. American Nephrology Nurses Association Journal, 10, 16. 
APPENDIX A

Instrument 
DIALYSIS SCREENING TOOL

1. Patient demonstrates positive mood, and independence, and determination, and careful attention to self-care. 3 2

2. Patient demonstrates ability to test reality understands own motives and actions.

3

2 1

0

3. Patient demonstrates positive cognitive function clear sensorium.

3

2

1

0

4. Patient has positive body image. Has incorporated concept of peritoneal catheter into this image.

3 2

1

0

5. Patient demonstrates previous ability to handle crisis. 3 2 1 0

6. Patient demonstrates good tolerance for environmental stresses. 3

2

1

0

7. Patient demonstrates strong personality structure meticulous/obsessive compulsive. 3 2 1 0

8. Patient has support and acceptance of treatment by relatives/significant others.

3

2

1

0

Strongly

Moderately

Minimally

Absent 
APPENDIX B

Interview Guide 
INTERVIEW OBJECTIVES

Patient is to understand that information sought is their personal perception of their success with home dialysis, and what personal factors contributed to this success.

1. Patient's perception of degree of success with home peritoneal dialysis.

2. Patient's perception of personal strengths or characteristics that significantly affected this degree of success.

3. Patient's perception of what personal strengths or characteristics should be identified as indicators of probable success with home peritoneal dialysis in themselves, and other prospective home peritoneal dialysis patients.

4. To what degree does patient feel the following characteristics predict success with home peritoneal dialysis:

Positive mode, independence, and determination;

Personal understanding of motives and actions; 
Clear sensorium;

Positive body image;

Ability to handle and cope with crisis;

Good tolerance for environmental stresses;

Strong personality structure;

Support and acceptance of treatment by relatives and significant others;

5. Patient's perception of most important factor in their personal success with home peritoneal dialysis. 


\section{APPENDIX C}

Reliability of Tool 


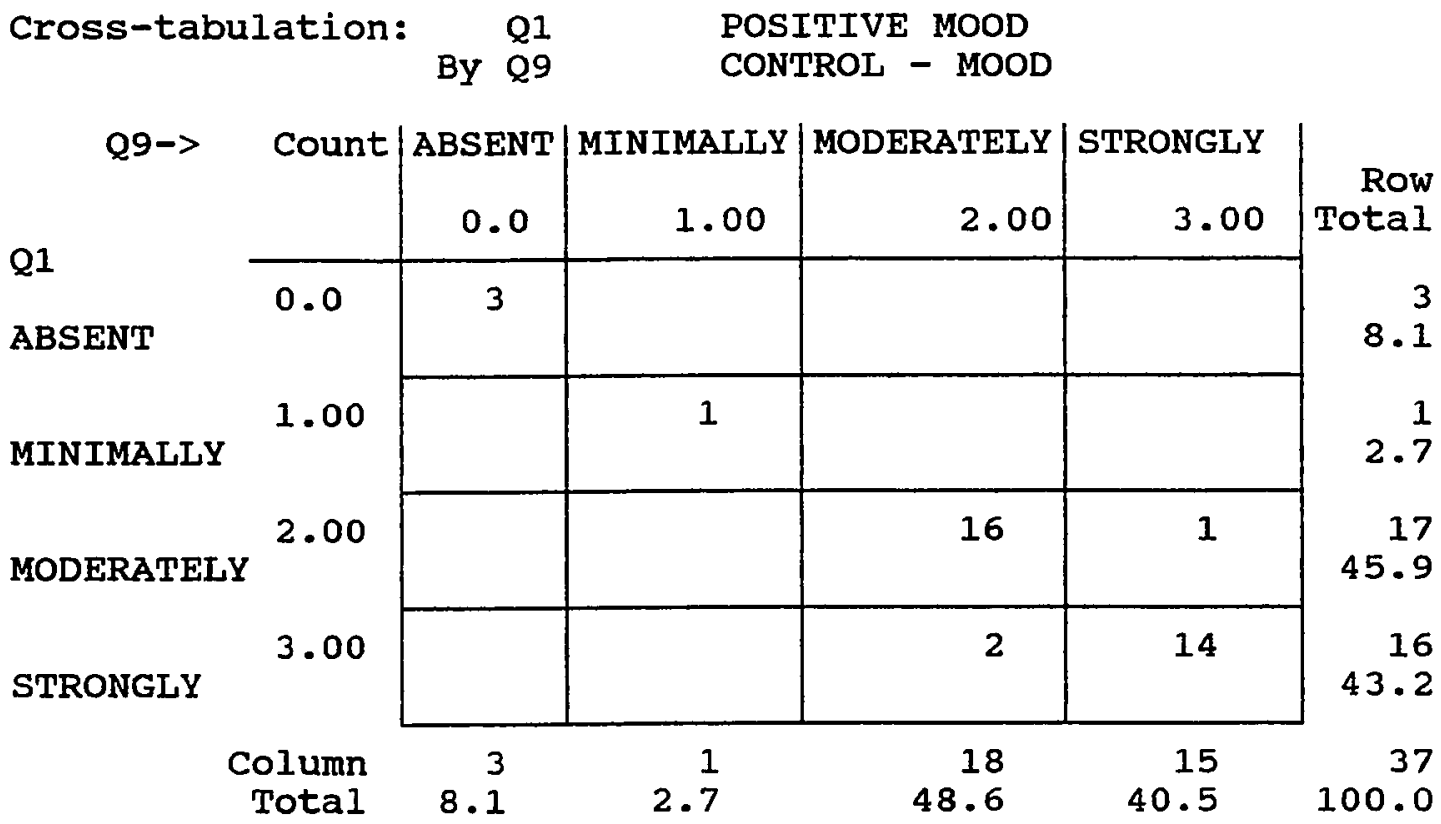

Statistic

Kendall's Tau B

\section{Value}

.87931

Number of Missing Observations = 


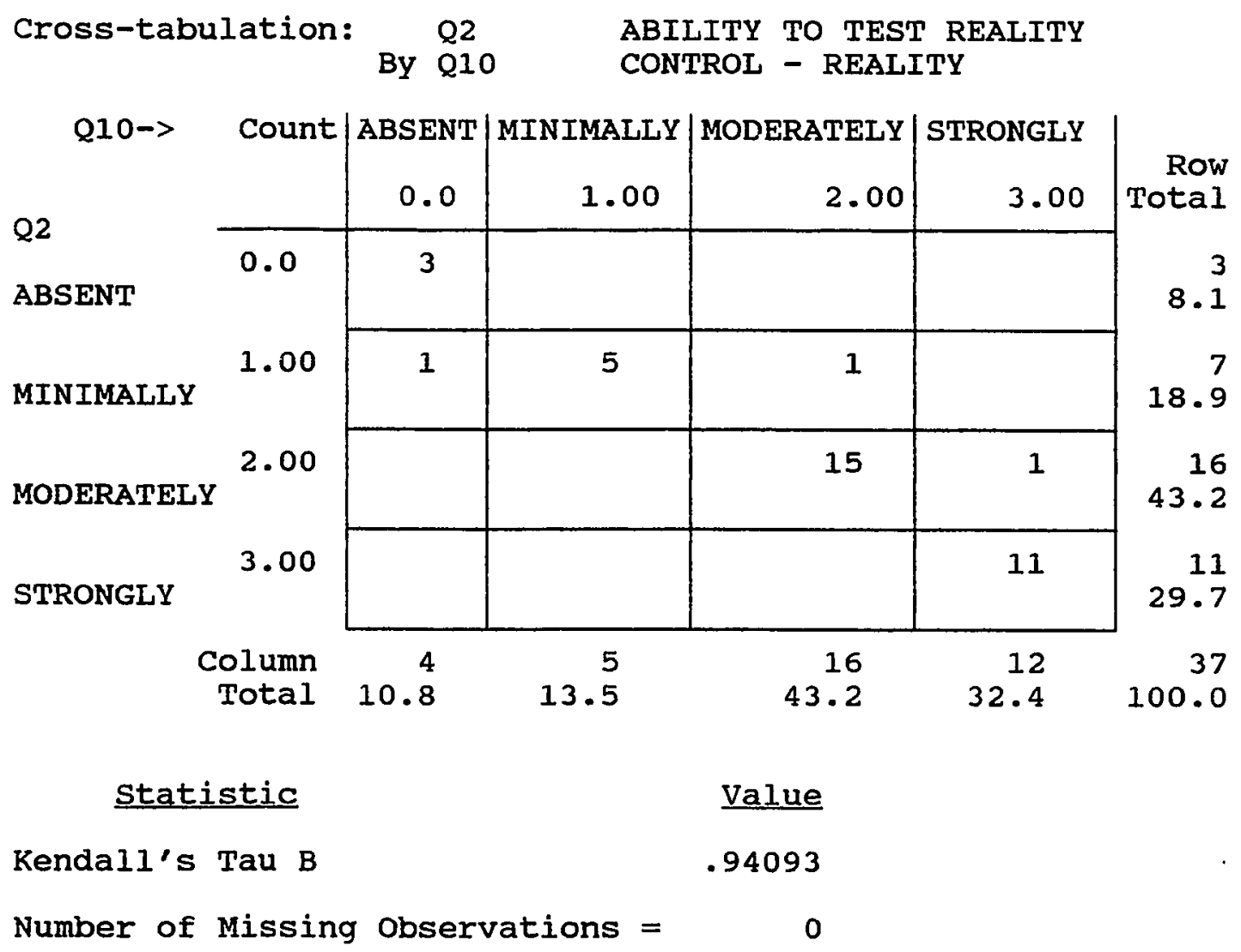




\begin{tabular}{|c|c|c|c|c|c|c|}
\hline \multicolumn{2}{|c|}{ Cross-tabulation: } & By $\stackrel{Q 3}{Q 11}$ & \multicolumn{4}{|c|}{$\begin{array}{l}\text { POSITIVE COGNITIVE FUNCTION } \\
\text { CONTROL - COGNITIVE FUNCTION }\end{array}$} \\
\hline Q11-> & Count & $\begin{array}{c}\text { ABSENT } \\
0.0\end{array}$ & $\begin{array}{c}\text { MINIMALLY } \\
1.00\end{array}$ & $\begin{array}{r}\text { MODERATELY } \\
2.00\end{array}$ & $\begin{array}{r}\text { STRONGLY } \\
3.00\end{array}$ & $\begin{array}{r}\text { Row } \\
\text { Total }\end{array}$ \\
\hline ABSENT & 0.0 & 3 & & & & \\
\hline MINIMALLY & 1.00 & 1 & 4 & 2 & & 18. \\
\hline MODERATELY & 2.00 & & & 16 & 1 & $45^{1}$ \\
\hline TRONGLY & 3.00 & & & & 10 & $27^{1}$ \\
\hline & $\begin{array}{l}\text { olumn } \\
\text { rotal }\end{array}$ & $\begin{array}{r}4 \\
10.8\end{array}$ & $\begin{array}{r}4 \\
10.8\end{array}$ & $\begin{array}{r}18 \\
48.6\end{array}$ & $\begin{array}{r}11 \\
29.7\end{array}$ & $100^{3}$ \\
\hline
\end{tabular}

Statistic

Kendall's Tau B
Value

.91744

Number of Missing Observations = 


\begin{tabular}{|c|c|c|c|c|c|c|}
\hline \multicolumn{2}{|c|}{ Cross-tabulation: } & $\begin{array}{ll}\text { Q4 } \\
\text { By } & \text { Q12 }\end{array}$ & \multicolumn{3}{|c|}{$\begin{array}{l}\text { POSITIVE BODY IMAGE } \\
\text { CONTROL - BODY IMAGE }\end{array}$} & \multirow[b]{2}{*}{$\begin{array}{r}\text { Row } \\
\text { Total }\end{array}$} \\
\hline Q12-> & Count & $\begin{array}{c}\text { ABSENT } \\
0.0\end{array}$ & $\begin{array}{r}\text { MINIMALLY } \\
1.00\end{array}$ & $\begin{array}{r}\text { MODERATELY } \\
2.00\end{array}$ & $\begin{array}{r}\text { STRONGLY } \\
3.00\end{array}$ & \\
\hline ABSENT & 0.0 & 3 & & & & $\begin{array}{r}3 \\
8.1\end{array}$ \\
\hline MINIMALLY & 1.00 & 1 & 3 & & & $\begin{array}{r}4 \\
10.8\end{array}$ \\
\hline MODERATELY & 2.00 & & & 7 & 3 & $\begin{array}{r}10 \\
27.0\end{array}$ \\
\hline STRONGLY & 3.00 & & & 1 & 19 & $\begin{array}{r}20 \\
54.1\end{array}$ \\
\hline & $\begin{array}{l}\text { lumn } \\
\text { lotal }\end{array}$ & 10.8 & 8.1 & $\begin{array}{r}8 \\
21.6\end{array}$ & $\begin{array}{r}22 \\
59.5\end{array}$ & $\begin{array}{r}37 \\
100.0\end{array}$ \\
\hline
\end{tabular}

statistic

Kendall's Tau B

Number of Missing Observations =
Value

.85158 


\begin{tabular}{|c|c|c|c|c|c|c|}
\hline \multirow{2}{*}{$\begin{array}{c}\text { Cross-tabu } \\
\text { Q13-> }\end{array}$} & lation: & By $\stackrel{\mathrm{Q5}}{\mathrm{Q} 13}$ & \multicolumn{3}{|c|}{ ABILITY TO HANDLE CRISIS } & \multirow[b]{2}{*}{$\begin{array}{r}\text { Row } \\
\text { Total }\end{array}$} \\
\hline & count & $\begin{array}{c}\text { ABSENT } \\
0.0\end{array}$ & $\begin{array}{r}\text { MINIMALLY } \\
1.00\end{array}$ & $\begin{array}{r}\text { MODERATELY } \\
2.00\end{array}$ & $\begin{array}{r}\text { STRONGLY } \\
3.00\end{array}$ & \\
\hline ABSENT & 0.0 & 1 & & & & 2.7 \\
\hline MINIMALLYY & 1.00 & 2 & 1 & & & $8.1^{3}$ \\
\hline MODERATELY & 2.00 & & & 21 & & $\begin{array}{r}21 \\
56.8\end{array}$ \\
\hline STRONGLY & 3.00 & & & 1 & 11 & $\begin{array}{r}12 \\
32.4\end{array}$ \\
\hline & $\begin{array}{l}\text { olumn } \\
\text { Total }\end{array}$ & $\begin{array}{r}3 \\
8.1\end{array}$ & $\begin{array}{r}1 \\
2.7\end{array}$ & $\begin{array}{r}22 \\
59.5\end{array}$ & $\begin{array}{r}11 \\
29.7\end{array}$ & $\begin{array}{r}37 \\
100.0\end{array}$ \\
\hline
\end{tabular}

Statistic

Kendall's Tau B
Value

.95296

Number of Missing Observations = 


\begin{tabular}{|c|c|c|c|c|c|c|}
\hline \multicolumn{2}{|c|}{ Cross-tabulation: } & $\begin{array}{ll} & \mathrm{Q6} \\
\text { By } & \mathrm{Q} 14\end{array}$ & \multicolumn{3}{|c|}{ TOLERANCE FOR STRESS } & \\
\hline Q14-> & count & $\mid \begin{array}{c}\text { ABSENT } \\
0.0\end{array}$ & $\begin{array}{r}\text { MINIMALLY } \\
1.00\end{array}$ & $\begin{array}{r}\text { MODERATELY } \\
2.00\end{array}$ & $\begin{array}{r}\text { STRONGLY } \\
3.00\end{array}$ & $\begin{array}{r}\text { Row } \\
\text { Total }\end{array}$ \\
\hline BSENT & 0.0 & 1 & & & & $\begin{array}{r}1 \\
2.7\end{array}$ \\
\hline INIMALLY & 1.00 & 1 & 3 & 1 & & $\begin{array}{r}5 \\
13.5\end{array}$ \\
\hline ODERATELY & 2.00 & & 1 & 18 & 1 & $\begin{array}{r}20 \\
54.1\end{array}$ \\
\hline TRONGLY & 3.00 & & & 1 & 10 & $\begin{array}{r}11 \\
29.7\end{array}$ \\
\hline & $\begin{array}{l}\text { olumn } \\
\text { Total }\end{array}$ & $\begin{array}{r}2 \\
5.4\end{array}$ & $\begin{array}{r}4 \\
10.8\end{array}$ & $\begin{array}{r}20 \\
54.1\end{array}$ & $\begin{array}{r}11 \\
29.7\end{array}$ & $\begin{array}{r}37 \\
100.0\end{array}$ \\
\hline
\end{tabular}

Statistic Value

Kendall's Tau B $\quad .86304$

Number of Missing Observations $=\quad 0$ 


\begin{tabular}{|c|c|c|c|c|c|c|}
\hline \multicolumn{2}{|c|}{ Cross-tabulation: } & $\begin{array}{ll}\mathrm{Q7} \\
\text { By } & \mathrm{Q} 15\end{array}$ & \multicolumn{3}{|c|}{$\begin{array}{l}\text { PERSONALITY STRUCTURE } \\
\text { CONTROL - PERSONALITY }\end{array}$} & \multirow[b]{2}{*}{$\begin{array}{r}\text { Row } \\
\text { Total }\end{array}$} \\
\hline Q15-> & Count & $\begin{array}{c}\text { ABSENT } \\
0.0\end{array}$ & $\begin{array}{c}\text { MINIMALLY } \\
1.00\end{array}$ & $\begin{array}{r}\text { MODERATELY } \\
2.00\end{array}$ & $\begin{array}{r}\text { STRONGLY } \\
3.00\end{array}$ & \\
\hline BSENT & 0.0 & 2 & & & & $\begin{array}{r}2 \\
5.4\end{array}$ \\
\hline INIMALLY & 1.00 & 2 & 2 & 1 & & $\begin{array}{r}5 \\
13.5\end{array}$ \\
\hline MODERATELY & 2.00 & & & 16 & 1 & $\begin{array}{r}17 \\
45.9\end{array}$ \\
\hline TRONGLY & 3.00 & & & & 13 & $\begin{array}{r}13 \\
35.1\end{array}$ \\
\hline & $\begin{array}{l}\text { Dlumn } \\
\text { Cotal }\end{array}$ & $\begin{array}{r}4 \\
10.8\end{array}$ & $\begin{array}{r}2 \\
5.4\end{array}$ & $\begin{array}{r}17 \\
45.9\end{array}$ & $\begin{array}{r}14 \\
37.8\end{array}$ & $\begin{array}{r}37 \\
100.0\end{array}$ \\
\hline
\end{tabular}

statistic

Kendall's Tau B

Number of Missing Observations =
Value

.93476

0 


\begin{tabular}{|c|c|c|c|c|c|}
\hline \multicolumn{2}{|c|}{ Cross-tabulation: } & $\begin{array}{l}\text { Q8 } \\
\text { By } \\
\text { Q16 }\end{array}$ & CONTROL & \multicolumn{2}{|c|}{ - SUPPORT } \\
\hline Q16-> & count & $\begin{array}{c}\text { MINIMALLY } \\
1.00\end{array}$ & $\begin{array}{r}\text { MODERATELY } \\
2.00\end{array}$ & $\begin{array}{r}\text { STRONGLY } \\
3.00\end{array}$ & $\begin{array}{r}\text { Row } \\
\text { Total }\end{array}$ \\
\hline MINIMAILY & 1.00 & 1 & & & $\begin{array}{r}1 \\
2.7\end{array}$ \\
\hline MODERATELY & 2.00 & & 5 & 1 & $\begin{array}{r}6 \\
16.2\end{array}$ \\
\hline STRONGLY & 3.00 & & 2 & 28 & $\begin{array}{r}30 \\
81.1\end{array}$ \\
\hline & $\begin{array}{l}\text { lumn } \\
\text { rotal }\end{array}$ & $\begin{array}{r}1 \\
2.7\end{array}$ & $\begin{array}{r}7 \\
18.9\end{array}$ & $\begin{array}{r}29 \\
78.4\end{array}$ & $100.0^{37}$ \\
\hline
\end{tabular}

Statistic

Kendall's Tau B

Number of Missing Observations =
Value

.76581

0 
APPENDIX D

Frequency Graphs 


$\begin{array}{rrrrrr}\text { Value Label } & \text { Value } & \text { Frequency } & \text { Percent } & \begin{array}{r}\text { Valid } \\ \text { Percent }\end{array} & \begin{array}{c}\text { Cum } \\ \text { Percent }\end{array} \\ 2.00 & 1 & 2.7 & 2.7 & 2.7 \\ 5.00 & 1 & 2.7 & 2.7 & 5.4 \\ 6.00 & 1 & 2.7 & 2.7 & 8.1 \\ 9.00 & 1 & 2.7 & 2.7 & 10.8 \\ 10.00 & 1 & 2.7 & 2.7 & 13.5 \\ 14.00 & 2 & 5.4 & 5.4 & 18.9 \\ 15.00 & 2 & 5.4 & 5.4 & 24.3 \\ 16.00 & 4 & 10.8 & 10.8 & 35.1 \\ 17.00 & 4 & 10.8 & 10.8 & 45.9 \\ 18.00 & 1 & 2.7 & 2.7 & 48.6 \\ 19.00 & 2 & 5.4 & 5.4 & 54.1 \\ 20.00 & 6 & 16.2 & 16.2 & 70.3 \\ 21.00 & 3 & 8.1 & 8.1 & 78.4 \\ 22.00 & 1 & 2.7 & 2.7 & 81.1 \\ 23.00 & 1 & 2.7 & 2.7 & 83.8 \\ 24.00 & 6 & 16.2 & 16.2 & 100.0 \\ & & & & & \end{array}$

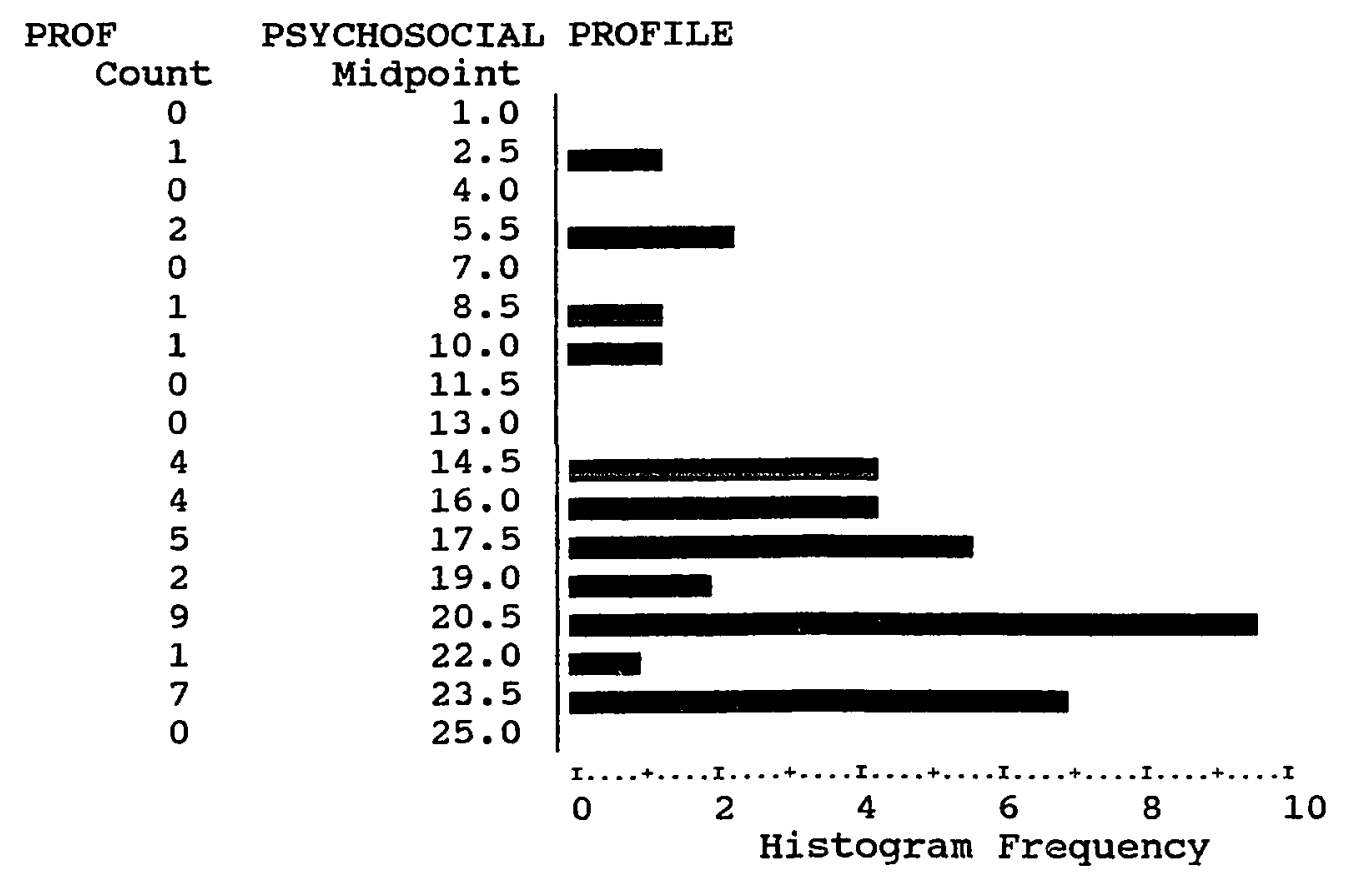


Q17 LENGTH OF TREATMENT

$\begin{array}{rrrrrr}\text { Value Label } & \text { Value } & \text { Frequency } & \text { Percent } & \begin{array}{r}\text { Valid } \\ \text { Percent }\end{array} & \begin{array}{c}\text { Cum } \\ \text { Percent }\end{array} \\ 1.00 & 6 & 16.2 & 16.2 & 16.2 \\ 5.00 & 1 & 2.7 & 2.7 & 18.9 \\ 6.00 & 3 & 8.1 & 8.1 & 27.0 \\ 7.00 & 4 & 10.8 & 10.8 & 37.8 \\ 8.00 & 2 & 5.4 & 5.4 & 43.2 \\ 10.00 & 1 & 2.7 & 2.7 & 45.9 \\ 11.00 & 1 & 2.7 & 2.7 & 48.6 \\ 12.00 & 2 & 5.4 & 5.4 & 54.1 \\ 13.00 & 3 & 8.1 & 8.1 & 62.2 \\ 14.00 & 1 & 2.7 & 2.7 & 64.9 \\ 15.00 & 4 & 10.8 & 10.8 & 75.7 \\ 16.00 & 4 & 10.8 & 10.8 & 86.5 \\ 26.00 & 1 & 2.7 & 2.7 & 89.2 \\ 31.00 & 1 & 2.7 & 2.7 & 91.9 \\ 32.00 & 1 & 2.7 & 2.7 & 94.6 \\ 42.00 & 1 & 2.7 & 2.7 & 97.3 \\ 44.00 & 1 & 2.7 & 2.7 & 100.0 \\ & & & & & \\ & \text { TOTAL } & 37 & 100.0 & 100.0 & \end{array}$

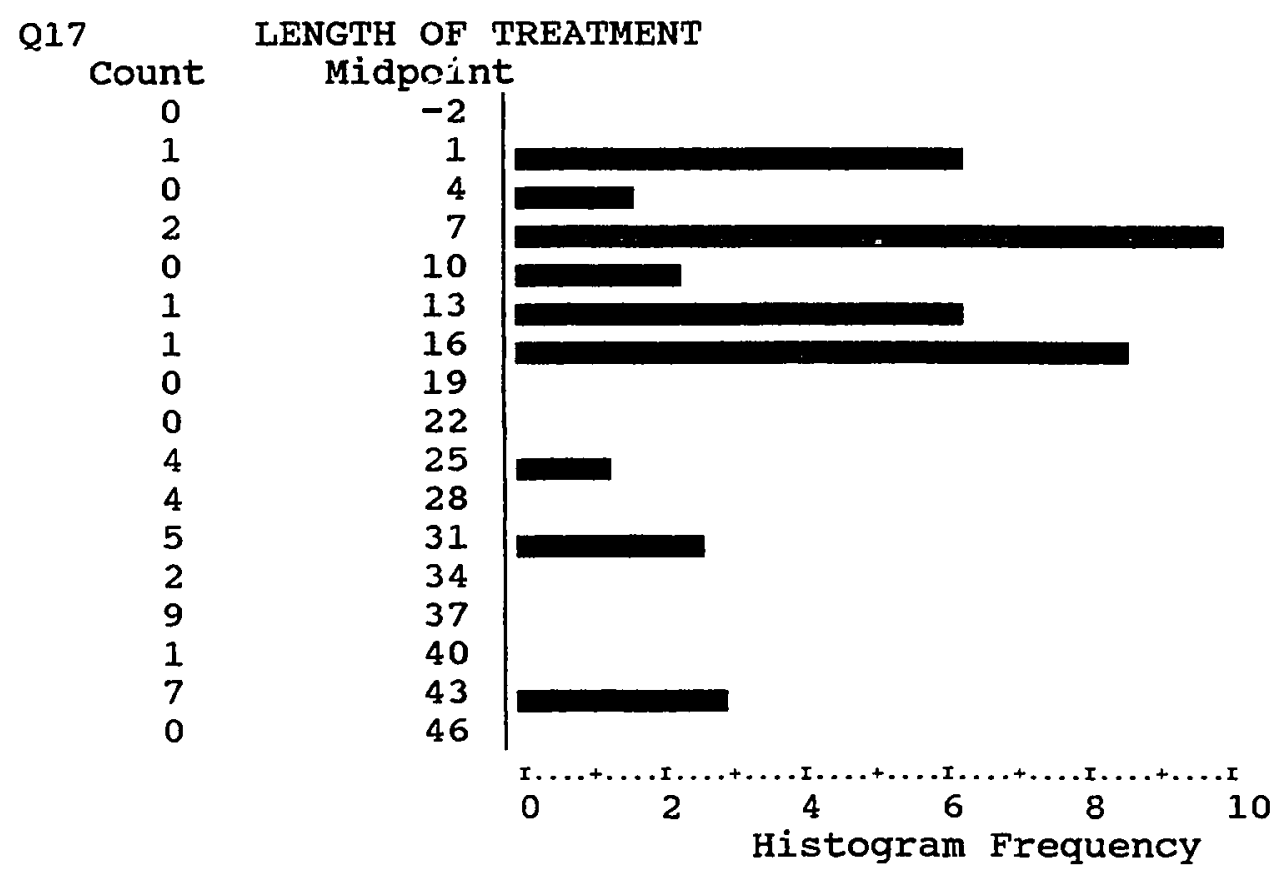




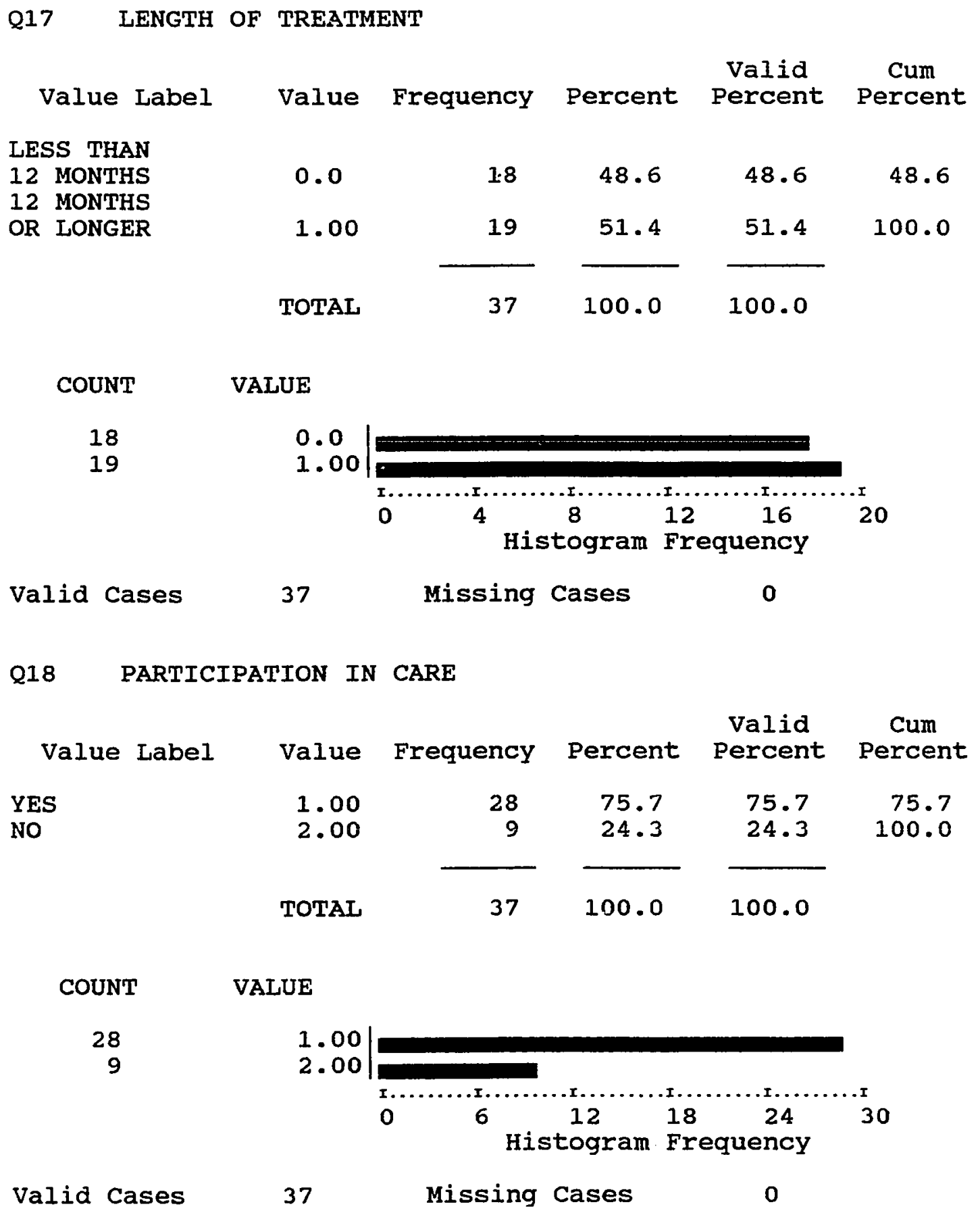


Q19 LOW PERITONITIS RATE

\begin{tabular}{|c|c|c|c|c|c|}
\hline Value Label & Value & Frequency & Percent & $\begin{array}{l}\text { Valid } \\
\text { Percent }\end{array}$ & $\begin{array}{l}\text { Cum } \\
\text { Percent }\end{array}$ \\
\hline \multirow[t]{2}{*}{$\begin{array}{l}\text { YES } \\
\text { NO }\end{array}$} & $\begin{array}{l}1.00 \\
2.00\end{array}$ & $\begin{array}{r}29 \\
8\end{array}$ & $\begin{array}{l}78.4 \\
21.6\end{array}$ & $\begin{array}{l}78.4 \\
21.6\end{array}$ & $\begin{array}{r}78.4 \\
100.0\end{array}$ \\
\hline & TOTAL & 37 & 100.0 & 100.0 & \\
\hline COUNT & VALUE & & & & \\
\hline $\begin{array}{r}29 \\
8\end{array}$ & $\begin{array}{l}1.00 \\
2.00\end{array}$ & … & & & \\
\hline & & $\begin{array}{lll} & \\
& & \\
& & \end{array}$ & $=0$ & $\begin{array}{c}24 \\
\text { equency }\end{array}$ & $\begin{array}{l}. r \\
30\end{array}$ \\
\hline Valid Cases & 37 & Missing & Cases & 0 & \\
\hline
\end{tabular}

Q20 CONSTANT FUNCTIONAL LEVEL

\begin{tabular}{|c|c|c|c|c|c|}
\hline Value Label & Value & Frequency & Percent & $\begin{array}{l}\text { Valid } \\
\text { Percent }\end{array}$ & $\begin{array}{l}\text { Cum } \\
\text { Percent }\end{array}$ \\
\hline \multirow[t]{2}{*}{$\begin{array}{l}\text { YES } \\
\text { NO }\end{array}$} & $\begin{array}{l}1.00 \\
2.00\end{array}$ & $\begin{array}{r}30 \\
7\end{array}$ & $\begin{array}{l}81.1 \\
18.9\end{array}$ & $\begin{array}{l}81.1 \\
18.9\end{array}$ & $\begin{array}{r}81.1 \\
100.0\end{array}$ \\
\hline & TOTAL & 37 & 100.0 & 100.0 & \\
\hline COUNT & VALUE & & & & \\
\hline $\begin{array}{r}30 \\
7\end{array}$ & $\begin{array}{l}1.00 \\
2.00\end{array}$ & & & & \\
\hline & & 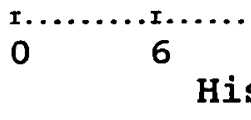 & 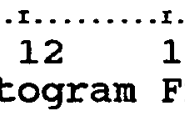 & $\begin{array}{c}24 \\
\text { equency }\end{array}$ & . 30 \\
\hline Valid Cases & 37 & Missing & Cases & 0 & \\
\hline
\end{tabular}


Q21 ACCEPTABLE LAB VALUES

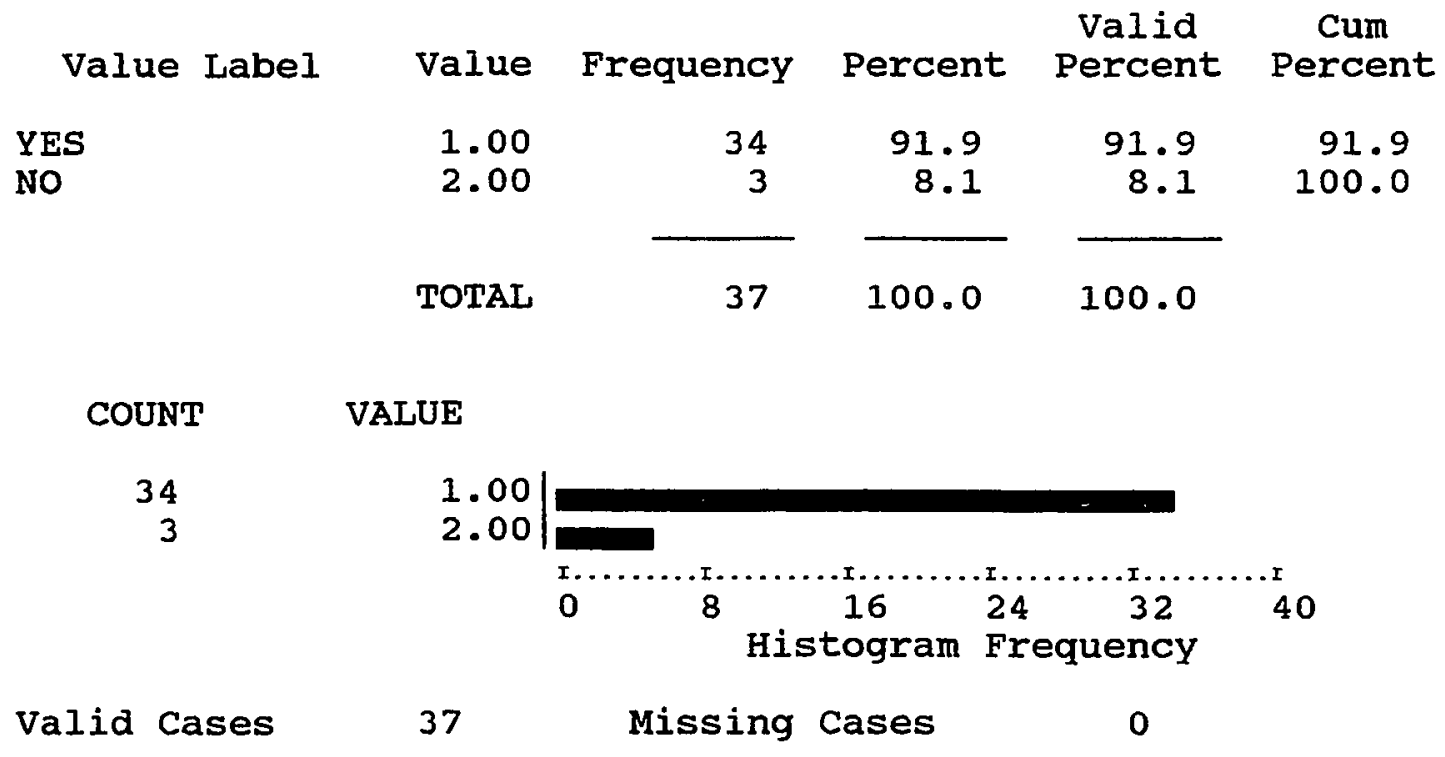


Q22 HOW TREATMENT ENDED

\begin{tabular}{|c|c|c|c|c|c|}
\hline Value Label & Value & Frequency & Percent & $\begin{array}{l}\text { Valid } \\
\text { Percent }\end{array}$ & $\begin{array}{l}\text { Cum } \\
\text { Percent }\end{array}$ \\
\hline $\begin{array}{l}\text { TRANSPLANT } \\
\text { DEATH } \\
\text { CEASE } \\
\text { CONTINUES }\end{array}$ & $\begin{array}{l}1.00 \\
2.00 \\
3.00 \\
4.00\end{array}$ & $\begin{array}{r}7 \\
8 \\
9 \\
13\end{array}$ & $\begin{array}{l}18.9 \\
21.6 \\
24.3 \\
35.1\end{array}$ & $\begin{array}{l}18.9 \\
21.6 \\
24.3 \\
35.1\end{array}$ & $\begin{array}{r}18.9 \\
40.5 \\
64.9 \\
100.0\end{array}$ \\
\hline & TOTAL & 37 & 100.0 & 100.0 & \\
\hline COUNT & VALUE & & & & \\
\hline $\begin{array}{r}7 \\
8 \\
9 \\
13\end{array}$ & $\begin{array}{l}1.00 \\
2.00 \\
3.00 \\
4.00\end{array}$ & & 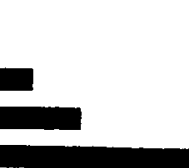 & & \\
\hline & & ${ }^{\mathrm{Hi}}$ & $\begin{array}{ll}8 & 12 \\
=0 \text { ogram } & \text { Fr }\end{array}$ & $\begin{array}{c}16 \\
\text { equency }\end{array}$ & 20 \\
\hline Valid Cases & 37 & Missing & :ases & 0 & \\
\hline
\end{tabular}


SUCCESS SUCCESS OF THE TREATMENT

\begin{tabular}{|c|c|c|c|c|c|}
\hline Value Label & Value & Frequency & Percent & $\begin{array}{l}\text { Valid } \\
\text { Percent }\end{array}$ & $\begin{array}{l}\text { Cum } \\
\text { Percent }\end{array}$ \\
\hline \multirow[t]{2}{*}{$\begin{array}{l}\text { YES } \\
\text { NO }\end{array}$} & $\begin{array}{l}0.0 \\
1.00\end{array}$ & $\begin{array}{l}19 \\
18\end{array}$ & $\begin{array}{l}51.4 \\
48.6\end{array}$ & $\begin{array}{l}51.4 \\
48.6\end{array}$ & $\begin{array}{r}51.4 \\
100.0\end{array}$ \\
\hline & TOTAL & 37 & 100.0 & 100.0 & \\
\hline COUNT & VALUE & & & & \\
\hline $\begin{array}{l}19 \\
18\end{array}$ & $\begin{array}{l}0.0 \\
1.00\end{array}$ & & & & \\
\hline & & 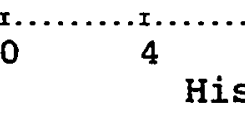 & $\begin{array}{cc}8 & 1 \\
\text { togram } & \end{array}$ & $\begin{array}{c}16 \\
q u e n c y\end{array}$ & $\begin{array}{l}. r \\
20\end{array}$ \\
\hline Valid Cases & 37 & Missing & Cases & 0 & \\
\hline
\end{tabular}


Q23 PATIENT'S AGE

\begin{tabular}{|c|c|c|c|c|c|}
\hline Value Label & Value & Frequency & Percent & $\begin{array}{l}\text { Valid } \\
\text { Percent }\end{array}$ & $\begin{array}{l}\text { Cum } \\
\text { Percent }\end{array}$ \\
\hline & 23.00 & 1 & 2.7 & 2.7 & 2.7 \\
\hline & 25.00 & 1 & 2.7 & 2.7 & 5.4 \\
\hline & 31.00 & 1 & 2.7 & 2.7 & 8.1 \\
\hline & 32.00 & 1 & 2.7 & 2.7 & 10.8 \\
\hline & 34.00 & 1 & 2.7 & 2.7 & 13.5 \\
\hline & 35.00 & 1 & 2.7 & 2.7 & 16.2 \\
\hline & 39.00 & 1 & 2.7 & 2.7 & 18.9 \\
\hline & 40.00 & 2 & 5.4 & 5.4 & 24.3 \\
\hline & 41.00 & 1 & 2.7 & 2.7 & 27.0 \\
\hline & 42.00 & 1 & 2.7 & 2.7 & 29.7 \\
\hline & 44.00 & 1 & 2.7 & 2.7 & 32.4 \\
\hline & 48.00 & 2 & 5.4 & 5.4 & 37.8 \\
\hline & 52.00 & 2 & 5.4 & 5.4 & 43.2 \\
\hline & 54.00 & 1 & 2.7 & 2.7 & 45.9 \\
\hline & 56.00 & 1 & 2.7 & 2.7 & 48.6 \\
\hline & 57.00 & 1 & 2.7 & 2.7 & 51.4 \\
\hline & 58.00 & 1 & 2.7 & 2.7 & 54.1 \\
\hline & 62.00 & 2 & 5.4 & 5.4 & 62.2 \\
\hline & 63.00 & 2 & 5.4 & 5.4 & 67.6 \\
\hline & 65.00 & 4 & 10.8 & 10.8 & 78.4 \\
\hline & 66.00 & 1 & 2.7 & 2.7 & 81.1 \\
\hline & 68.00 & 1 & 2.7 & 2.7 & 83.8 \\
\hline & 72.00 & 1 & 2.7 & 2.7 & 86.5 \\
\hline & 73.00 & 2 & 5.4 & 5.4 & 91.9 \\
\hline & 74.00 & 1 & 2.7 & 2.7 & 94.6 \\
\hline & 76.00 & 1 & 2.7 & 2.7 & 97.3 \\
\hline & 81.00 & 1 & 2.7 & 2.7 & 100.0 \\
\hline & TOTAL & 37 & 100.0 & 100.0 & \\
\hline
\end{tabular}




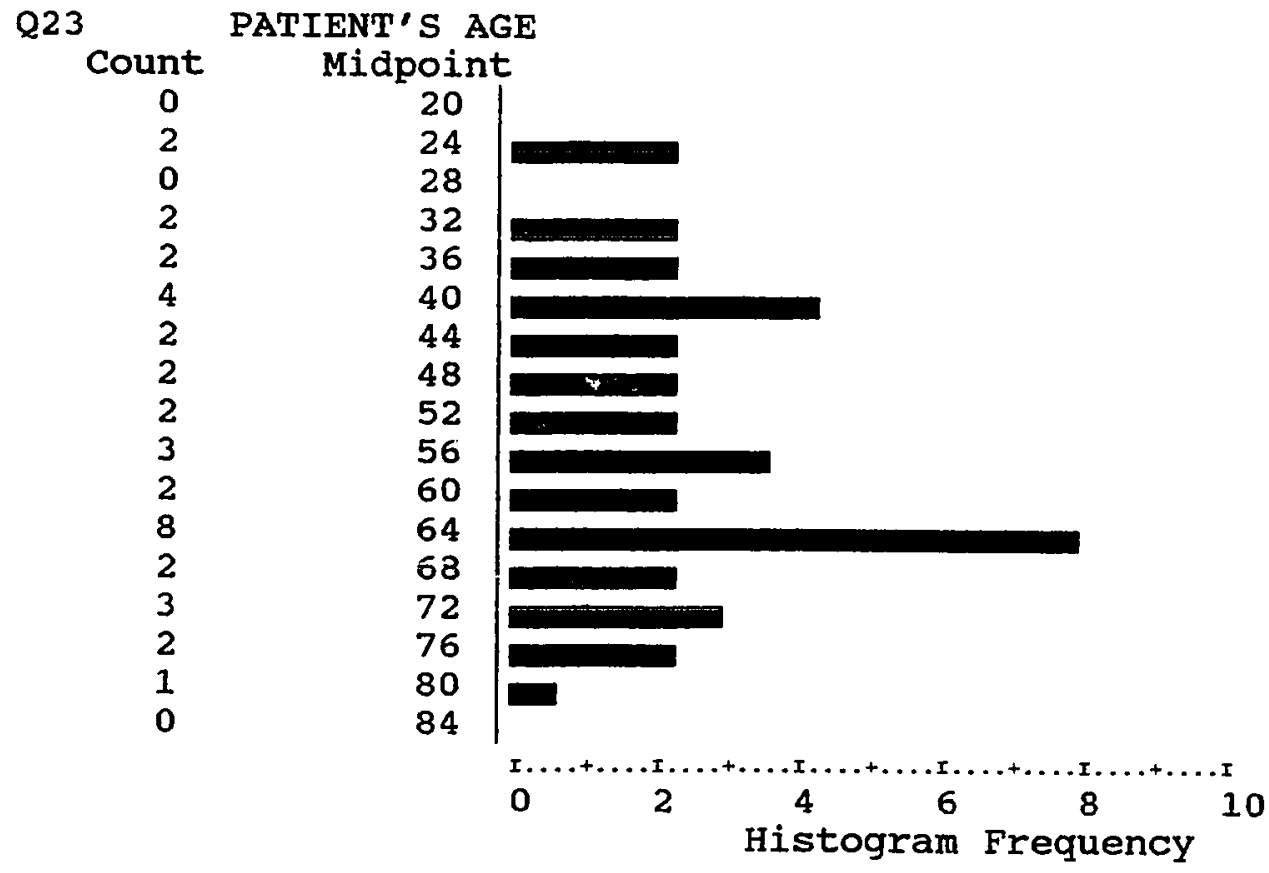

Valid Cases

37

Missing Cases

0 


\section{APPENDIX E}

Analysis of Variance 
Variable PROF DIALYSIS SCREENING TOOL

By Variable success

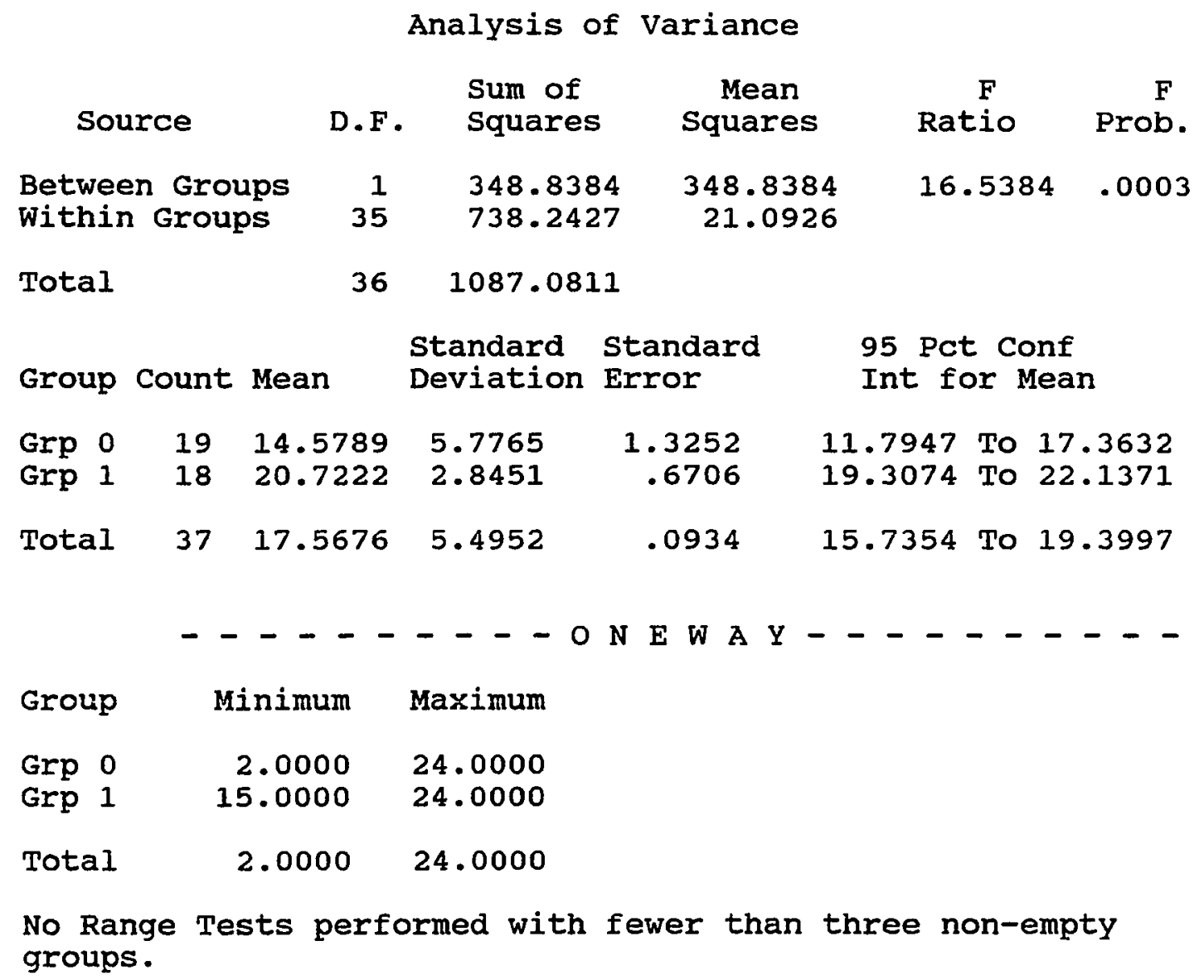


Independent samples of SUCCESS

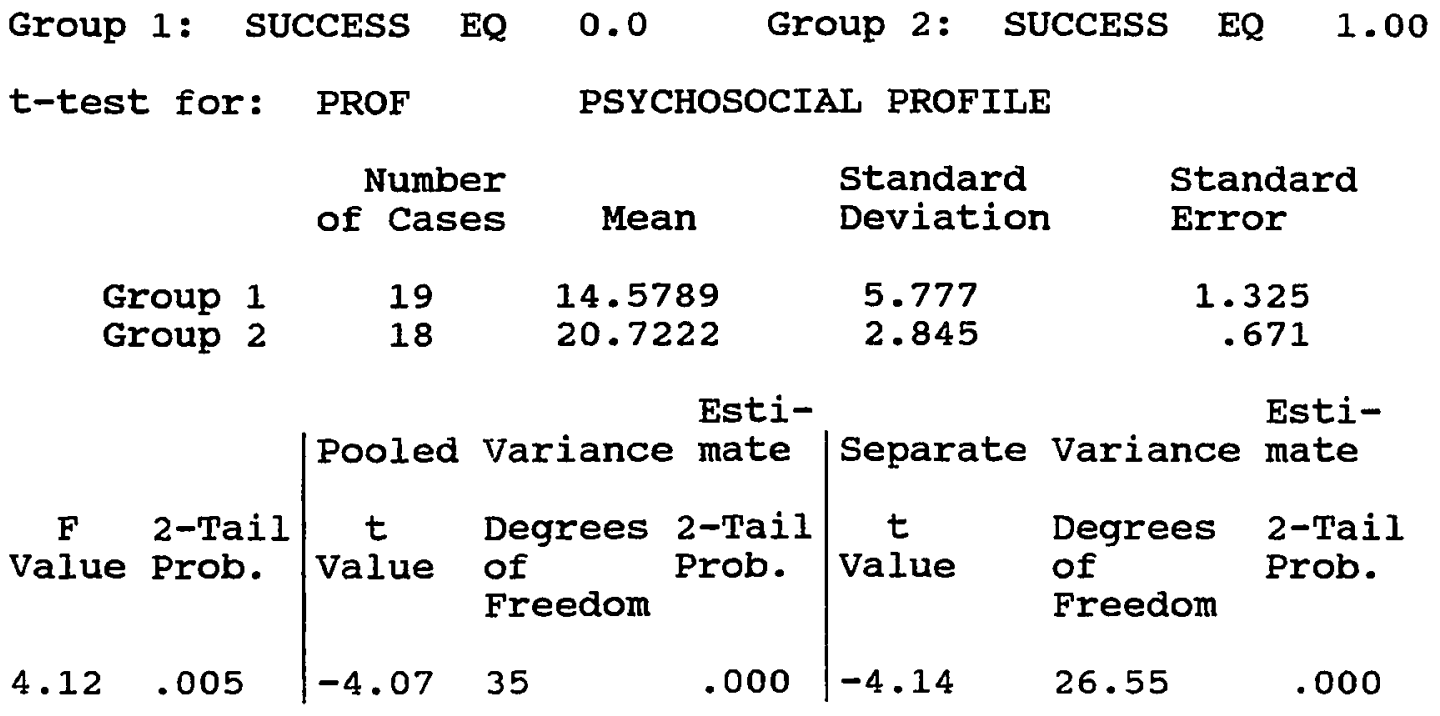




\section{APPENDIX F}

Consent Form 
PARTICIPATION AGREEMENT - RESEARCH PROJECT - SAN JOSE STATE UNIVERSITY

RESPONSIBLE INVESTIGATOR: Susan Healy, RN, CNN

TITLE OF PROTOCOL: Evaluation of a Tool to Predict Success with CAPD

I have been asked to participate in a research study that is investigating the development of a tool to assist dialysis staff in predicting which patients have the best chance of succeeding with home peritoneal dialysis. The results of this study should further our understanding of which patients should attempt to train for home dialysis. If we are better able to understand which patients will succeed with home dialysis, we can possibly prevent some of the frustration and disappointment met by patients that attempt home peritoneal dialysis, and do not succeed.

I understand that:

1. I will be asked to participate in an interview with the researcher to try to identify what characteristics I might have that have helped me to succeed with home peritoneal dialysis. 
2. There are no risks identified with my participation in this study. All aspects of my interview with the researcher will be kept confidential, and will not be included in or on my chart, or shared with my care givers. All notes taken at the interview will be placed in a coded file that does not include my name, or other identifying information.

3. The possible benefits of this study for me are the opportunities to discuss with the researcher what I feel has helped me be successful with home peritoneal dialysis, and the awareness that I may help other dialysis patients choose the right form of therapy by helping the researcher collect this information.

4. No standard treatments or procedures are altered or withheld from me due to my participation in this study.

5. The results from this study may be published, but any information from this study that can be identified with me will remain confidential and will be disclosed only with my permission or as required by law.

6. No compensation will be paid me for participation in this project. 
7. Any questions about my participation in this study will be answered by Susan Healy, R.N., C.N.N. Phone number: 408-758-6222. Complaints about the procedures may be presented to Susan Murphy, R.N., M.S., D.N.S. Phone number: 415-969-3452. For questions or complaints about research subject's rights, or in the event of a research related injury, contact Serena stanford, Ph.D. Phone number: $408-924-2480$.

8. My consent is given voluntarily without being coerced; I may refuse to participate in this study or in any part of this study, and I may withdraw at any time, without prejudice to my relations with San Jose State University, Salinas Valley Dialysis Services, Inc., or the primary researcher, Susan Healy.

9. I have received a copy of this consent form for my file.

I HAVE MADE A DECISION WHETHER OR NOT TO PARTICIPATE. MY SIGNATURE INDICATES THAT I HAVE READ THE INFORMATION PROVIDED ABOVE AND THAT I HAVE DECIDED TO PARTICIPATE. 